Este libro forma parte del acervo de la Biblioteca Jurídica Virtual del Instituto de Investigaciones Jurídicas de la UNAM

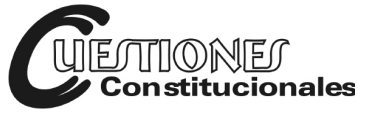

Revista Mexicana de Derecho Constitucional

Núm. 26, enero-junio 2012

\title{
LAS FUENTES FORMALES DEL DERECHO PARLAMENTARIO Y SU NORMATIVIDAD CONSTITUCIONAL EN MÉXICO
}

\author{
FORMAL SORCES OF PARLAMENTARY LAW \\ AND CONSTITUTIONAL NORMS IN MÉXICO
}

\author{
Susana Thalía Pedroza de LA LlaVE*
}

RESUMEN: Este artículo proporciona, de manera completa y propositiva, y con relación a su estudio, análisis y jerarquía normativa, tanto a las personas especialistas en la materia como al público en general, cuáles son los antecedentes del derecho parlamentario y su concepto, así como dar respuesta al por qué este término se debe emplear no sólo para un sistema o régimen. Asimismo, se abordan las fuentes del derecho y las fuentes del derecho parlamentario, en especial las fuentes formales y actuales del mismo y su normatividad constitucional en México. Por la brevedad con la que se desarrollan los temas anteriores, se hace un esfuerzo de sistematización de las fuentes formales del derecho parlamentario. De igual forma, se realiza un análisis descriptivo, pues éste resulta muy pertinente debido a que constantemente este tema es requerido para su estudio, tanto por las personas especialistas en la materia como por el público en general.

Palabras clave: Derecho parlamentario, fuentes del derecho parlamentario, normatividad del Congreso General de los Estados Unidos Mexicanos, Constitución mexicana, Congreso General Mexicano.

* Investigadora en el Instituto de Investigaciones Jurídicas de la UNAM. Agradezco el invaluable apoyo de Carolina Miranda Luévano para el desarrollo de este trabajo.
ABSTRACT: This article provides a full and purposeful, and in relation to their study, analysis and hierarchy of norms, both persons skilled in the art and the public overall, what is the background of parliamentary law and its concept, as well as responding to why this term should be used not only for a system or regime. It also deals with the sources of law and sources of parliamentary law, especially formal sources and presents yourself and your constitutional regulations in Mexico. For brevity with which they develop the above issues, there is an effort to systematize the formal sources of parliamentary law. Similarly, an analysis descriptive as this is very relevant because this topic is constantly required for study, both by those skilled in the art and the public at large.

Descriptors: Parliamentary law, sources of parliamentary law, standardization of the General Congress of the United Mexican Sta- tes, Mexican-Constitution, General Mexican Congress. 


\section{CONSIDERACIÓN INTRODUCTORIA}

El presente artículo pretende proporcionar de manera original, completa y propositiva, y en relación con su estudio, análisis y jerarquía normativa, tanto a las personas especialistas en la materia como al público en general, primero, cuáles son los antecedentes del derecho parlamentario y su concepto, y dar respuesta al por qué este término se debe emplear no sólo para un sistema o régimen parlamentario, sino también para uno presidencial, a pesar de que el primer sistema tenga un Parlamento y, el segundo, un Congreso.

Asimismo, en segundo término, este artículo tiene por objeto abordar también las fuentes del derecho y las fuentes del derecho parlamentario, para después referirnos en su totalidad, a un tema en específico de manera amplia y profunda, poco estudiado y abordado por la doctrina mexicana, y analizado de manera integral y presentado como producto y/o propuesta de investigación y en un sólo documento claro, sistematizado y no disperso en nuestro país por los autores y autoras que nos dedicamos al derecho parlamentario mexicano: las fuentes formales y actuales de este derecho y su normatividad constitucional en México, como son la Constitución Política de los Estados Unidos Mexicanos de 1917 vigente, los tratados internacionales, la Ley Orgánica del Congreso General de los Estados Unidos Mexicanos de 1999, el Reglamento del Congreso (o Reglamento para el Gobierno Interior del Congreso General Mexicano de 1934), y los recientes reglamentos, tanto del Senado de la República de 2010 como el Reglamento de la Cámara de Diputados también de 2010. Para ello, se señala el marco general de cómo se ordenan, el contenido de los anteriores, los cambios que éstos han tenido, o las nuevas normas o cuáles son sus posibles modificaciones a la normatividad ya existente.

De igual manera, en tercer término, nos referiremos a otras fuentes formales y que son menos conocidas de dicho derecho parlamentario en México como son el Reglamento del Canal de Televisión del Congreso General de los Estados Unidos Mexicanos; el Estatuto de la Organización Técnica y Administrativa y del Servicio de Carrera de la Cámara de Diputados; el Estatuto del Servicio Civil de Carrera del Senado; el Estatuto para los Servicios Parlamentarios, Administrativos y Técnicos del Senado de la República; los Reglamentos Interiores de las Comisiones Legislativas y otros Reglamentos; los acuerdos parlamentarios y los puntos de acuerdo; los usos, prácticas y costumbres parlamentarias; los Manuales de Organización, de 
Procedimientos o de Servicios al Público y las Condiciones Generales de Trabajo; los Estatutos de los Partidos y de las Fracciones o Grupos Parlamentarios; la jurisprudencia, y la doctrina y otras fuentes.

La utilidad que se pretende aportar con esta investigación es que, a lo largo de este artículo, se realiza la sistematización exclusiva de las fuentes formales del derecho parlamentario y también se desarrolla el análisis descriptivo de dichas fuentes formales pues éste resulta muy pertinente debido a que constantemente este tema es requerido para su estudio (y en varios sectores, público y privado) y para realizar investigaciones en el ámbito del derecho constitucional comparado, tanto por las personas especialistas en la materia como por el público en general, integrado en un sólo documento, que trata de ser completo, claro y ordenado sobre cuáles son las fuentes formales del derecho parlamentario en México. Asimismo, partiendo de la consideración que una Constitución, de cualquier país, siempre enuncia las fuentes y plantea una estructura del sistema en que tales fuentes se integran, durante el desarrollo de este trabajo se pretende verificar si ese es también el caso de México.

Finalmente, en este trabajo se señalan algunas propuestas y conclusiones para un mejor desarrollo y avance en el conocimiento y jerarquía de las fuentes formales del derecho parlamentario y su normatividad constitucional en México, partiendo de la idea que en la actualidad existe una tendencia en otros países para establecer constitucionalmente el sistema de fuentes en el ámbito parlamentario, con el propósito de tener una mayor claridad en la materia.

\section{EL DERECHO PARLAMENTARIO Y LAS FUENTES DEL DERECHO}

Por una parte, si realizamos un análisis histórico, el derecho parlamentario tiene sus orígenes en Estados Unidos, país que cuenta con un sistema o régimen presidencial —en lugar de uno parlamentario-y con la existencia de un Congreso y no de un Parlamento. Lo anterior se afirma porque fue en Estados Unidos en donde se elaboró y publicó una obra compilada por Tomas Jefferson, en 1827, titulada Manual del derecho parlamentario, o resumen de las reglas que se observan en el Parlamento de Inglaterra y en el Congreso de los Estados Unidos para la proposición, discusión y decisión de los negocios. El propósito de Jefferson era poner en conocimiento de los nuevos representantes y senadores los 
elementos teórico-prácticos, para que ellos resolviesen los casos dudosos y difíciles.

Por otra parte, tenemos que dentro de las definiciones que se han expuesto respecto del derecho parlamentario se encuentra la de Silvano Tosi, quien lo considera como "parte del derecho constitucional que se refiere a la organización interna y al funcionamiento del parlamento". ${ }^{1}$ Sin embargo, para Fernando Santaolalla el derecho parlamentario es el "conjunto de normas que regulan la organización y funcionamiento de las Cámaras parlamentarias, entendidas como órganos que asumen la representación popular en un Estado constitucional y democrático de derecho y el ejercicio de sus funciones supremas". ${ }^{2}$ Santaolalla precisa que este derecho gira en torno a una determinada institución, pero que no es suficiente que la misma se denomine "Parlamento", siendo ésta una denominación de carácter accesorio y lo esencial, según este autor y estando totalmente de acuerdo con él, es que dicha institución encarne libre y democráticamente la voluntad popular, es decir, que cuando se hace referencia al derecho parlamentario puede tratarse también de un Congreso, de una Asamblea, etcétera, y no sólo de un Parlamento, además es una disciplina del derecho constitucional que existe tanto en los sistemas o regímenes presidenciales como en los parlamentarios.

Después de esta definición, tenemos que las fuentes del derecho se catalogan en sociológicas, normativas y axiológicas. ${ }^{3}$ De manera formal, dichas fuentes son entendidas como las construcciones teóricas mediante las cuales se materializan las normas jurídicas. Una Constitución, de cualquier país, no se limita a enunciar las fuentes del derecho, sino que plantea una estructura del sistema en que tales fuentes se integran. Así, la Constitución no sólo define el modo de creación de las normas, sino también el conjunto de relaciones existentes entre éstas. Por ello, en realidad, no hay título, capítulo, etcétera, de un texto constitucional que se refiera expresamente a la configuración de fuentes, pero con la interpre-

1 Berlín Valenzuela, Francisco, Derecho parlamentario, México, Fondo de Cultura Económica, 1993, p. 25, citando a Silvano Tosi, Diritto parlamentare, Milán, Giuffrè, 1993, p. 3.

2 Santaolalla, Fernando, Derecho parlamentario español, Madrid, Espasa Calpe, 1990, p. 29.

3 Cfr. Garabito Martínez, Jorge, "Las fuentes axiológicas del derecho parlamentario”, Quórum Legislativo, México, núm. 75-76, abril-junio de 2003, pp. 30 y ss. 
tación sistemática de sus artículos se observa cuáles son las fuentes del derecho. ${ }^{4} \mathrm{~A}$ ese respecto, el estudio de los diferentes sistemas constitucionales de fuentes del derecho es uno de los temas principales de la doctrina constitucional del siglo XXI. ${ }^{5}$ Por lo anterior, apoyamos la propuesta que proporciona el Instituto de Investigaciones Jurídicas de la Universidad Nacional Autónoma de México en el sentido de que es necesario "establecer constitucionalmente el sistema de fuentes en el ámbito parlamentario", ${ }^{6}$ con ello se tendría una mayor claridad en la materia.

Conforme a estudios sobre filosofía del derecho en México, ${ }^{7}$ las fuentes del derecho se clasifican en fuentes formales; fuentes materiales o reales, y las fuentes históricas. Las fuentes formales se refieren a los procesos de creación y manifestación de las normas jurídicas, como son la legislación, la jurisprudencia y la costumbre; las fuentes materiales o reales del derecho son las condiciones o circunstancias históricas, factores y elementos que se dan en cierta época, los cuales influyen en el contenido de las normas jurídicas. Y, finalmente, las fuentes históricas se refieren a los documentos que contienen el texto de una norma o el conjunto de normas jurídicas. ${ }^{8}$

En este sentido, y para ejemplificar cada una de las fuentes que consideramos del derecho parlamentario mexicano, podemos retomar, y considerando que las fuentes materiales o reales son las condiciones históricas que se dan en cierta época y momentos determinados y que inciden en la

4 Cfr. Aguiar de Luque, Luis y Pérez Tremps, Pablo (dirs.), Veinte años de jurisdicción constitucional en España, Valencia, Tiran lo Blanch, 2002, pp. 67 y 68.

5 Cfr. Carbonell, Miguel, Constitución, reforma constitucional y fuentes del derecho en México, México, Porrúa-UNAM, 2008, p. 3, y del mismo autor, "El significado de las fuentes del derecho, una perspectiva constitucional", Quórum Legislativo, México, núm. 75-76, abril-junio de 2003, pp. 50 y ss.

6 Fix-Fierro, Héctor, Carpizo, Jorge, Valadés, Diego et al., en Barceló Rojas, Daniel (coord.), La Reforma del Estado. Propuesta del IIJ-UNAM para la actualización de las relaciones entre poderes del sistema presidencial mexicano, México, UNAM, Instituto de Investigaciones Jurídicas-Senado de la República, 2009, pp. 33 y 34.

7 Como son, por ejemplo, los estudios de García Máynez, Eduardo, Introducción al estudio del derecho, 42a. ed., México, Porrúa, 1991, pp. 51 y ss.; Villoro Toranzo, Miguel, Introducción al estudio del derecho, 2a. ed., México, Porrúa, 1990, pp. 161 y ss., y Recaséns Siches, Luis, Introducción al estudio del derecho, 2a. ed., México, Porrúa, 1990, pp. 169 y ss.

8 Idem. 
creación y contenido de las normas jurídicas; ${ }^{9}$ por ejemplo, entonces serán la Revolución francesa de $1789,{ }^{10}$ la independencia norteamericana de 1776, la colonización española, la independencia de 1810, las ideas centralistas, federalistas y liberales, el porfiriato, la Revolución mexicana de 1910, el proceso de transición jurídica hacia la democracia iniciado a finales de los años setenta y principios de los ochenta, la participación social, ${ }^{11}$ las elecciones de 1997, 2000 y las posteriores, etcétera.

Mientras que las fuentes históricas se refieren a los documentos que contienen tales normas jurídicas o la evidencia histórica que permite su conocimiento; ${ }^{12}$ por ejemplo, la Declaración Francesa de 1789, la Declaración de los Derechos del Buen Pueblo de Virginia de 1776, la Constitución norteamericana de 1787, la Constitución de Cádiz de 1812, la de 1814, de 1824, las Leyes Constitucionales de 1836, la Constitución de 1857, la reforma constitucional de 1874, la Constitución de 1917 que reforma a la de 1857, el Diario Oficial de la Federación, el Diario de los Debates ${ }^{13}$ de cada una de las cámaras, entre otras similares publicaciones.

Tratándose de las fuentes formales, éstas serán la Constitución; los tratados internacionales; las leyes; los reglamentos; los estatutos; los acuerdos parlamentarios y los puntos de acuerdo; la costumbre, la práctica o el hábito parlamentario; la jurisprudencia relativa a la institución representativa mexicana, así como la doctrina, siempre y cuando la disposición legislativa la hubiera tomado en consideración. A estas fuentes nos referiremos a continuación.

9 Cfr. Salinas Torre, Armando, "Reflexiones sobre las fuentes del derecho parlamentario mexicano", Quórum Legislativo, México, núm. 75-76, abril-junio de 2003, p. 11.

10 Incluso se pueden considerar otros documentos anteriores, como el surgido en 1689, denominado el Bill of Rights, cfr. Aranda Álvarez, Elvira, "Claves para entender el concepto y las fuentes del derecho parlamentario", Revista de las Cortes Generales, Madrid, núm. 66, tercer cuatrimestre de 2005, pp. 10-14.

11 Respecto a este tema, consúltese Quiroga Lavié, Humberto, "El derecho parlamentario en la ciencia jurídica”, Derecho parlamentario iberoamericano, México, Porrúa, 1997, pp. 11 y ss.

12 Cfr. Pérez Noriega, Fernando, "Fuentes del derecho parlamentario", Quórum Legislativo, México, núm. 75-76, abril-junio de 2003, p. 16.

13 Cfr. Barragán, José, “Algunas consideraciones de carácter histórico sobre el régimen interno del Congreso de la Unión", Revista Mexicana de Estudios Parlamentarios, México, núm. 2, 1991, p. 118. 


\section{LAS FUENTES FORMALES DEL DERECHO PARLAMENTARIO Y SU NORMATIVIDAD CONSTITUCIONAL EN MÉXICO}

\section{La Constitución Política de los Estados Unidos Mexicanos de 1917 vigente}

Al igual que otros autores, ${ }^{14}$ nos parece importante en este trabajo que se refiere a las fuentes formales específicas del derecho parlamentario empezar por la Constitución. La misma, en cualquier país, se ubica como un criterio esencial de validez de las normas en el sistema jurídico. Así, la Constitución Política de los Estados Unidos Mexicanos, vigente desde 1917, es decir, hace más de 95 años, se caracteriza por ser una fuente del derecho ${ }^{15} \mathrm{y}$, por ser también, una fuente del derecho parlamentario, la cual se integra por 136 artículos y 19 transitorios. Ésta ha sido reformada, ${ }^{16}$ desde su origen y contando las reformas de 2001 a febrero de 2012, en más de 770 ocasiones, contando artículos, párrafos, incisos, apartados, etcétera.

En 2009 se estableció que toda persona tiene derecho al acceso a la cultura y al disfrute de los bienes y servicios que presta el Estado en la materia, así como el ejercicio de sus derechos culturales. Para ello, el Estado promoverá los medios para la difusión y desarrollo de la cultura, atendiendo a la diversidad cultural en todas sus manifestaciones y expresiones con pleno

${ }^{14}$ Por ejemplo, Carbonell, Miguel, op. cit., p. 5.

15 Cfr. Aguiar de Luque, Luis y Pérez Tremps, Pablo (dirs.), op. cit., pp. 67 y 68.

16 Para Arteaga Nava, Elisur, "Las Constituciones estatales y sus reformas", Alegatos, México, núm. 6, 1987, p. 4, las leyes pueden ser modificadas de tres formas: mediante adiciones; por supresiones y por modificaciones. Sin embargo, éstas, al final de cuentas, son reformas, $c f r$. Schmill Ordóñez, Ulises, El sistema de la Constitución mexicana, México, Porrúa, 1977, p. 151. En las últimas décadas se han modificado artículos que constitucionalistas mexicanos habían considerado "decisiones políticas fundamentales"; sin embargo, para otros estudiosos del tema, dichas reformas no trastocan "pilares fundacionales", además la realidad exigió su reforma, por ello, la Constitución es sólida, válida y vigente, cfr. Madrazo, Jorge, "Comentario al artículo 135", Constitución Política de los Estados Unidos Mexicanos. Comentada y concordada, 15a. ed., México, Porrúa-UNAM, t. V, 2000, pp. 144-153. Talavera, Abraham, "México: reforma política y reforma electoral”, Quórum, México, núm. 10, 1993, p. 46, citando a Lorenzo Meyer. Cfr. Cárdenas Gracia, Jaime F., Una Constitución para la democracia. Propuestas para un nuevo orden constitucional, México, UNAM, 1996. Cfr. Otto, Ignacio de, Derecho constitucional, Barcelona, Ariel, 1988, p. 46. Moreno Uriegas, María de los Ángeles, "El Poder Legislativo y el proyecto nacional”, Quórum, México, núm. 26, 1994, p. 49. 
respeto a la libertad creativa, y la ley establecerá los mecanismos para el acceso y participación a cualquier manifestación cultural; asimismo, con esa reforma se faculta al Congreso para que legisle en materia de protección de datos personales en posesión de particulares; también se le facultó al Congreso para establecer los delitos y las faltas contra la Federación y fijar los castigos que por ellos deban imponerse; expedir una ley general en materia de secuestro, que establezca, como mínimo, los tipos penales y sus sanciones, la distribución de competencias y las formas de coordinación entre la Federación, el Distrito Federal, los estados y los municipios, así como legislar en materia de delincuencia organizada.

En ese mismo año se estableció que toda persona tiene derecho a la protección de sus datos personales, al acceso, rectificación y cancelación de los mismos, así como a manifestar su oposición, en los términos que fije la ley, la cual establecerá los supuestos de excepción a los principios que rijan el tratamiento de datos, por razones de seguridad nacional, disposiciones de orden público, seguridad y salud públicas o para proteger los derechos de terceros. Determinándose también que no podrá librarse orden de aprehensión sino por la autoridad judicial y sin que preceda denuncia o querella de un hecho que la ley señale como delito, sancionado con pena privativa de libertad y obren datos que establezcan que se ha cometido ese hecho y que exista la probabilidad de que el indiciado lo cometió o participó en su comisión. ${ }^{17}$

También en 2009 se publicó la reforma mediante la cual los poderes federales Legislativo, Ejecutivo y Judicial, así como los organismos con autonomía reconocida por la Constitución, los poderes estatales Legislativo, Ejecutivo y Judicial, así como los organismos con autonomía reconocida en sus constituciones locales que ejerzan recursos del Presupuesto de Egresos de la Federación, deberán incluir dentro de sus proyectos de

17 Considerando las fracciones y párrafos, cfr. Constitución Política de los Estados Unidos Mexicanos, 5a. ed., México, Comisión Nacional de los Derechos Humanos, 2002; Constitución Política de los Estados Unidos Mexicanos, 165a. ed., México, Porrúa, 2012, y Fix-Zamudio, Héctor y Valencia Carmona, Salvador, Derecho constitucional mexicano y comparado, México, 7a. ed., Porrúa-UNAM, 2010. Cronológicamente había sido reformada, por ejemplo, por 153 decretos de reforma hasta el 12 de noviembre de 2002, cfr. Instituto de Investigaciones Jurídicas, Evolución de la Constitución Política de los Estados Unidos Mexicanos, http://www.juridicas.unam.mx/infjur/leg/constmex/; sin embargo, al 12 de abril de 2012 son 201 decretos de reforma, cfr. http://www.juridicas.unam.mx/ infjur/leg/constmex/, consultada el 26 de febrero de 2009, el 17 de agosto de 2009, el 19 de enero y 15 de abril de 2010, y el 12 de abril de 2012 . 
presupuestos, los tabuladores desglosados de las remuneraciones que se propone perciban sus servidores públicos. En cuanto a las legislaturas de los Estados, los presupuestos de egresos serán aprobados por los ayuntamientos con base en sus ingresos disponibles, y deberán incluir en los mismos, los tabuladores desglosados de las remuneraciones que perciban los servidores públicos municipales, sujetándose a lo dispuesto en el artículo 127 de la Constitución. De igual manera, ocurrirá respecto al presupuesto de egresos y la ley de ingresos del Distrito Federal. ${ }^{18}$

El 27 abril de 2010 se publicó la reforma al artículo 122 constitucional para crear el Consejo de Judicatura del Tribunal Superior de Justicia del Distrito Federal, así como el 29 julio de ese mismo año apareció publicada la reforma al artículo 17 constitucional con relación a que el Congreso de la Unión expedirá las leyes que regulen las acciones colectivas, en las cuales se determinarán las materias de aplicación, los procedimientos judiciales y los mecanismos de reparación del daño. Asimismo, se determina que los jueces federales conocerán de forma exclusiva sobre estos procedimientos y mecanismos, y que las leyes preverán mecanismos alternativos de solución de controversias. Por otra parte, en ese mismo artículo, se estableció que las sentencias que pongan fin a los procedimientos orales deberán ser explicadas en audiencia pública previa citación de las partes, y que tanto la Federación, los estados y el Distrito Federal garantizarán la existencia de un servicio de defensoría pública, en donde las percepciones de los defensores no podrán ser inferiores a los de los agentes del Ministerio Público. ${ }^{19}$

El 13 de abril de 2011 se reformó el artículo 43 constitucional. Sobre las recientes reformas a la Constitución, sin duda alguna, las de mayor trascendencia para todas y todos fueron las publicadas en el Diario Oficial de la Federación el 6 y 10 de junio de ese año, es decir, la reforma constitucional en materia de amparo (artículos 94, 103, 104 y 107) y la reforma constitucional en materia de derechos humanos (artículos 1o., 3o., 11, 15, 18, 29, 33, 89, 97, 102 y 105). Esta última ofrece a todas las personas un catálogo de derechos humanos más amplio al establecer que todos gozaremos de los derechos humanos que reconoce la Constitución,

18 Cfr. Diario Oficial de la Federación, del 24 de agosto de 2009.

19 Cfr. http://www.juridicas.unam.mx/infjur/leg/constmex/pdf/27042010R.pdf y http:// www.juridicas.unam.mx/infjur/leg/constmex/pdf/29072010R.pdf, consultadas el 30 de septiembre de 2010. 
pero también los tratados internacionales de los que el Estado mexicano sea parte. Con esta reforma, se dio el cambio de denominación del Capítulo I del Título Primero de la Constitución, siendo un acierto, porque es más adecuado llamarlo "De los Derechos Humanos y sus garantías," ya que deja claro que una cosa son los derechos reconocidos en la Constitución y otra las garantías de éstos. Lo que más llama la atención es que en el artículo 1o. se hace un reconocimiento expreso a que los Poderes del Estado, los Poderes en México estarán vinculados a los derechos humanos y a las libertades que reconoce la propia Constitución. Todas las autoridades, todos(as) los(as) servidores(as) públicos(as) como es el Poder Ejecutivo, Legislativo, Judicial, los entes administrativos, etcétera, tienen como obligación prevenir, investigar, sancionar y reparar el daño por violaciones a derechos humanos. Cabe resaltar, que ese tipo de normas ya se consagran en otras Constituciones de otros países como una cláusula a través de la cual todos los poderes públicos quedan vinculados a los derechos humanos por parte de la norma constitucional.

Así, si una autoridad que depende del Ejecutivo o del Judicial o del Legislativo violentó los derechos humanos está obligada, primero, a que se eviten hechos lamentables o tragedias relacionadas con la violación a los derechos humanos; segundo, que las mismas deben investigar quién cometió esos actos u omisiones, y ya que se tiene investigado es su obligación determinar quiénes son los presuntos culpables y sancionarlos. En ese contexto, el Estado tiene que reparar los daños, esto es, dar una indemnización, así como medidas que traten de mitigar el daño causado. A ese respecto, otro aspecto importante y que también sobresale es la reforma al artículo 29 de la Constitución sobre la restricción y suspensión de los derechos fundamentales y garantías. Lo hace muy específico: el presidente de la República puede declarar la suspensión de garantías, él es el único facultado, pero quien lo tiene que autorizar o aprobar es el Congreso de la Unión (ambas cámaras, la de Senadores y la de Diputados). Los decretos que él vaya elaborando deben ser revisados por la Suprema Corte de Justicia de la Nación (SCJN). Asimismo, y de acuerdo a la reforma, hay ciertos derechos humanos que no podrán restringirse ni suspenderse: los derechos a la no discriminación; el reconocimiento de la personalidad jurídica; a la vida; a la integridad personal; a la protección a la familia; al nombre; a la nacionalidad; los derechos de la niñez; los derechos políticos; las libertades de pensamiento, conciencia y de profe- 
sar creencia religiosa alguna; el principio de legalidad y retroactividad; la prohibición de la pena de muerte; la prohibición de la esclavitud y la servidumbre; la prohibición de la desaparición forzada y la tortura; ni las garantías judiciales indispensables para la protección de tales derechos. En esta materia se necesita la aprobación del Congreso y todas las normas que se vayan elaborando deben pasar de manera urgente por SCJN para ver si se violenta algún derecho humano o no.

Un mes después, el 14 de julio de 2011 se reforman los artículos 19, 20 y 73 constitucionales, y el 17 de agosto de ese mismo año se modifican los artículos 71, 72 y 78 relativos a las facultades de las cámaras y su Comisión Permanente. El 12 de octubre se reformaron los artículos 4o. y 73 de la Constitución, para establecer que en todas las decisiones y actuaciones del Estado se velará y cumplirá con el principio del interés superior de la niñez, garantizando de manera plena sus derechos. Este principio deberá guiar el diseño, ejecución, seguimiento y evaluación de las políticas públicas dirigidas a la niñez. Asimismo, se facultó al Congreso para expedir leyes que establezcan la concurrencia de la Federación, los estados, el Distrito Federal y los municipios, en el ámbito de sus respectivas competencias, en materia de derechos de niñas, niños y adolescentes, velando en todo momento por el interés superior de los mismos y cumpliendo con los tratados internacionales de la materia de los que México sea parte. Ese mismo día, mes y año, se estableció en la Constitución, en esos artículos 4o. y 73, que toda persona tiene derecho a la cultura física y a la práctica del deporte, que corresponde al Estado su promoción, fomento y estímulo conforme a las leyes en la materia, y se facultó al Congreso para legislar en materia de cultura física y deporte con objeto de cumplir lo previsto en el artículo 4o. de la Constitución, estableciendo la concurrencia entre la Federación, los estados, el Distrito Federal y los municipios; así como de la participación de los sectores social y privado.

Finalmente, el 13 de octubre de 2011, y el 8 y 9 de febrero de 2012 se reforma la Constitución con relación a la materia de un medio ambiente sano, el derecho agua, y la educación media superior se vuelve obligatoria. ${ }^{20}$

${ }^{20}$ Cfr. http://www.juridicas.unam.mx/infjur/leg/constmex/, consultada el 12 de abril de 2012 . 
Así, la Constitución de $1917^{21}$ es la que durante más tiempo ha regido la vida institucional de México. Es una norma escrita y rígida ${ }^{22}$ en cuanto a su procedimiento de reforma. Su modelo constitucional es la Constitución norteamericana de 1787, con aportes de la Constitución de Cádiz de 1812 (por ejemplo, se denominó a la Cámara baja como Cámara de Diputados y se estableció la Comisión Permanente). Aunque sobre este punto, cabe señalar, como dato histórico y jurídico, que la Constitución de 1917 es una reforma a la Constitución de 1857, ya que el encabezado de la primera así lo reconoce en su publicación en el Diario Oficial de la Federación del 5 de febrero de 1917.

La Constitución recoge todo un abanico de fuentes y, a su vez, principios relacionados con el sistema normativo que son parte de los principios generales del derecho; por ejemplo, el principio de legalidad, el de jerarquía normativa, la irretroactividad, la seguridad jurídica, la publicidad de las normas, la responsabilidad de los servidores públicos, ${ }^{23}$ los principios de igualdad y no discriminación, entre otros.

Nuestra Constitución configura la forma de Estado (federal); la forma y régimen de gobierno (República y presidencia ${ }^{24}$ respectivamente); la creación y atribución de competencias de los órganos del Estado, entre éstos el H. Congreso de la Unión o Congreso General. Así, en la Constitución se prevé la existencia de éste, su estructura, integración, organización, privilegios, estatutos, así como sus facultades y sus relaciones con el Poder Ejecutivo, con el Poder Judicial, con los Organismos Constitucionales Autónomos,

21 En el momento de su promulgación se le consideró una norma con importantes previsiones en materia de derecho social, cfr. Villabona, María Pilar, "La Constitución mexicana de 1917 y la española de 1931”, Revista de Estudios Políticos, Madrid, núm. 31-32, 1983, pp. 199 y ss.

22 De hecho, durante varios años fue flexible por haberse considerado como un fenómeno político y no jurídico, cfr. Cossío, José Ramón y Raigosa, Luis, "Régimen político e interpretación constitucional", Revista El País, México, marzo de 1996, p. 35.

23 Cfr. Aguiar de Luque, Luis y Pérez Tremps, Pablo (dirs.), op. cit., p. 71, y Sanz Pérez, Ángel L. y Villacorta Mancebo, Luis, "La costumbre, el uso y otras fuentes no escritas en el derecho parlamentario", Corts. Anuario De Derecho Parlamentario, Valencia, núm. 17, 2006, p. 303.

24 Para Diego Valadés, en el derecho comparado, se está dando la parlamentarización de los sistemas presidenciales, ya que instrumentos parlamentarios han sido adoptados por numerosos sistemas presidenciales; por ejemplo, el voto de confianza, las preguntas, las interpelaciones, la moción de cesura e, incluso, la disolución del Congreso, $c f r$. Valadés, Diego, La parlamentarización de los sistemas presidenciales, 2a. ed., México, UNAM-El Colegio Nacional, 2008, pp. IX-255. 
entre otros. Por ejemplo, los artículos 1o.- 4o., 19-21, 24, 26-29, 32, 37, 41, 44- 46, 49-79, 84-90, 93, 95-100, 102, 105, 108-114, 117-119, 121-123, $125,127,130-133$ y 135, hacen referencia al Congreso o a la Comisión Permanente o a alguna de las cámaras del mismo.

Como comentarios adicionales en esta materia, es conveniente señalar, por una parte, respecto a las normas preconstitucionales que éstas quedan derogadas cuando alguna o algunas disposiciones se opongan a lo establecido en la Constitución, pero si no la contradicen estas normas preconstitucionales son aplicables y si la contradicen son inaplicables. Por otra parte, en algunos países, existe la tendencia tratándose de derechos fundamentales que es posible la aplicación retroactiva de la Constitución, pero esto analizando caso por caso, teniendo en cuenta las generalidades del mismo, pero también se debe tener en cuenta que la Constitución fue creada bajo una legalidad anterior. ${ }^{25}$

\section{Los tratados internacionales}

Por una parte, en la actualidad, y en el ámbito internacional, se hace evidente cada día más la participación de los Parlamentos, Congresos, Asambleas, etcétera; se habla así de una diplomacia parlamentaria que surge por la necesidad de promover relaciones entre las naciones a diferentes niveles.

Los tratados internacionales que ha celebrado el Poder Ejecutivo y que han sido aprobados por la Cámara de Senadores son una fuente del derecho parlamentario; por ejemplo, el Tratado de Institucionalización del Parlamento Latinoamericano de 1987. A ese respecto, y por la integración de dicho Parlamento que son los propios parlamentarios nacionales quienes asisten, es necesaria la participación de la ciudadanía en el proceso para su integración, es decir, mediante el sufragio activo y pasivo, ya que si sólo participan los gobiernos entonces el proceso se estanca. Si participa la ciudadanía es un factor de legitimidad, situación que en la realidad no acontece, porque no está regulado de esta forma en dicho Tratado de Institucionalización del Parlamento Latinoamericano, ${ }^{26}$ situación que sí se presenta para la integración del Parlamento Europeo.

${ }^{25}$ Cfr. Valadés, Diego, op. cit., pp. 69 y 71.

${ }^{26}$ Cfr. Trobo, Jaime Mario, "Diplomacia parlamentaria, una nueva dimensión de la política exterior", Revista Parlamentaria Iberoamericana, Madrid, núm. 7, 1998, pp. 193, 199 y 205. 
Por otra parte, los tratados internacionales son instrumentos signados por el Presidente de la República y ratificados por el Senado, de conformidad con los artículos $76,{ }^{27} 89^{28}$ y $133^{29}$ de la Constitución, y con las demás leyes que nos rigen. En este ámbito, las obligaciones del Estado mexicano se han incrementado con la firma y ratificación de diversos instrumentos internacionales, sobre todo, en materia de derechos humanos. A diferencia de los tratados comerciales signados por nuestro país, los que no son de esta naturaleza establecen obligaciones del Estado frente a las personas que habitan o transitan en el territorio mexicano, así como la obligación de respetar sus derechos fundamentales y señalar cuáles son los límites de actuación del Estado.

En este sentido, la Corte Interamericana de Derechos Humanos ha señalado en su opinión consultiva OC 2/82, del 24 de septiembre de 1982, denominada "El efecto de las reservas sobre la entrada en vigencia de la Convención Americana", que los tratados modernos sobre derechos humanos, en general, y, en particular, la Convención Americana no son tratados multilaterales del tipo tradicional concluidos en función de un intercambio recíproco de derechos para el beneficio mutuo de los Estados contratantes, sino que su objeto y fin son la protección de los derechos fundamentales

27 “Artículo 76. Son facultades exclusivas del Senado: I. Analizar la política exterior desarrollada por el Ejecutivo Federal con base en los informes anuales que el Presidente de la República y el Secretario del Despacho correspondiente rindan al Congreso. Además, aprobar los tratados internacionales y convenciones diplomáticas que el Ejecutivo Federal suscriba, así como su decisión de terminar, denunciar, suspender, modificar, enmendar, retirar reservas y formular declaraciones interpretativas sobre los mismos; ...".

28 “Artículo 89. Las facultades y obligaciones del Presidente, son las siguientes: X. Dirigir la política exterior y celebrar tratados internacionales, así como terminar, denunciar, suspender, modificar, enmendar, retirar reservas y formular declaraciones interpretativas sobre los mismos, sometiéndolos a la aprobación del Senado. En la conducción de tal política, el titular del Poder Ejecutivo observará los siguientes principios normativos: la autodeterminación de los pueblos; la no intervención; la solución pacífica de controversias; la proscripción de la amenaza o el uso de la fuerza en las relaciones internacionales; la igualdad jurídica de los Estados; la cooperación internacional para el desarrollo; el respeto, la protección y promoción de los derechos humanos y la lucha por la paz y la seguridad internacionales; ".

29 “Artículo 133. Esta Constitución, las leyes del Congreso de la Unión que emanen de ella y todos los tratados que estén de acuerdo con la misma, celebrados y que se celebren por el Presidente de la República, con aprobación del Senado, serán la Ley Suprema de toda la Unión. Los Jueces de cada Estado se arreglarán a dicha Constitución, leyes y Tratados, a pesar de las disposiciones en contrario que pueda haber en las Constituciones o leyes de los Estados." 
de los seres humanos independientemente de su nacionalidad, tanto frente a su propio Estado como frente a los otros Estados contratantes. Al aprobar estos tratados, los Estados se someten a un orden legal dentro del cual éstos, por el bien común, asumen varias obligaciones, no en relación con otros Estados, sino hacia los individuos bajo su jurisdicción. ${ }^{30}$

Por lo que toca al reconocimiento que se da a los tratados internacionales firmados y ratificados por México, con la tesis de la SCJN, del 28 de octubre de 2000, se interpretó que los tratados internacionales, firmados y ratificados por México se ubican jerárquicamente por encima de las leyes federales y locales y, por lo mismo, en un segundo plano respecto de la Constitución. Esto significa que tanto los poderes legislativos como los poderes judiciales, tanto federales como locales, tendrán que fundar y motivar sus normas y resoluciones en dichos tratados. Sin embargo, lo anterior no es aun jurisprudencia, ${ }^{31}$ sino es una tesis. A ese respecto, en marzo de 2007, se dio la tesis aislada titulada "SUPREMACÍA CONSTITUCIONAL Y LEY SUPREMA DE LA UNIÓN. INTERPRETACIÓN DEL ARTÍCULO 133 CONSTITUCIONAL”, que a grandes rasgos menciona que la Constitución se ubica en la cúspide y, por debajo de ella, los tratados internacionales y las leyes generales.

Por otra parte, los tratados internacionales han enriquecido la esfera jurídica de las personas y obligan al Estado a cumplir, en sus diferentes ámbitos, con lo dispuesto en dichos instrumentos. ${ }^{32}$ Por ejemplo, la Convención sobre la Eliminación de todas las Formas de Discriminación contra la Mujer, de 18 de diciembre de 1979 (por sus siglas en inglés, CEDAW), ratificada por México el 23 de marzo de 1980, y su Protocolo Facultativo, de 6 de octubre de 1999, establecieron el Comité de la CEDAW, que ha emitido Recomendaciones Generales, en donde destaca la Recomendación General núm. 12, emitida en su 8o. periodo de sesiones de 1989, que señala

30 Cfr. García Ramírez, Sergio (coord.), La Jurisprudencia de la Corte Interamericana de Derechos Humanos, México, UNAM-CIDH, 2001, p. 913.

31 Constituye jurisprudencia de la Suprema Corte de Justicia de la Nación (SCJN), cinco resoluciones ininterrumpidas en un mismo sentido, con cuando menos ocho votos si es el Pleno o cuatro si es la Sala. También constituye jurisprudencia la resolución del Pleno de la SCJN que dilucida la contradicción de tesis entre las Salas de la Corte o entre los Tribunales Colegiados.

32 Cfr. Pedroza de la Llave, Susana Thalía y García Huante, Omar (comps.), Compilación de instrumentos internacionales de derechos humanos. Firmados y ratificados por México 1921-2003, México, CNDH, ts. I y II, 2004, pp. 1-764 (t. I) y pp. 1-712 (t. II). (2000 ejemplares), la cual se integra por 108 instrumentos, de los cuales 32 son declaraciones y 76 son tratados internacionales, y tiene un total páginas 1476. 
en los artículos 2o., 5o., 11o., 120. y 16o. de la CEDAW la obligación de los Estados Partes de proteger a la mujer contra cualquier tipo de violencia que se produzca en la familia, en el trabajo o en cualquier otro ámbito de la vida social, y se solicita que se informe acerca de la "legislación vigente" para proteger a la mujer de cualquier tipo de violencia en la vida cotidiana (la violencia sexual, malos tratos en el ámbito familiar, acoso sexual en el lugar de trabajo, etcétera).

De igual manera, dicho Comité de la CEDAW emitió la Recomendación General núm. 19, en el 11o. periodo de sesiones de 1992, para que "en la legislación" y en las políticas que se instrumenten se prevenga y sancione la violencia; ${ }^{33}$ la Recomendación General núm. 21 sobre la igualdad en el matrimonio y en las relaciones familiares de 1994; la Recomendación General núm. 23 sobre vida pública y vida privada de 1997; la Recomendación General núm. 24 sobre la mujer y la salud, así como la Recomendación General núm. 28, del 29 de marzo de 2000, que reconoce que la desigualdad que padecen las mujeres en el mundo, en cuanto al disfrute de sus derechos, está profundamente arraigada a la tradición, la historia y la cultura, lo que deriva en que uno de los objetivos del desarrollo del milenio de la Organización de las Naciones Unidas sea precisamente la promoción de la igualdad entre los sexos y la autonomía de la mujer. ${ }^{34}$

Por lo anterior, y con la firma de tratados internacionales, han surgido o se ha dado origen en nuestro país a importantes leyes federales; por ejemplo, la Ley del Instituto Nacional de las Mujeres, publicada en el Diario Oficial de la Federación, el 12 de enero de 2001 y que entró en vigor el 13 del mismo mes y año; la Ley Federal para Prevenir y Eliminar la Discriminación, publicada en el Diario Oficial de la Federación, el 11 de junio de 2003; la Ley General para la Igualdad entre Mujeres y Hombres, que se publicó el 2 de agosto de 2006; la Ley General de Acceso de las Mujeres a una Vida Libre de Violencia, publicada en el Diario Oficial de la Federación, el 1o. de febrero de 2007 (reformada el 20 de enero de 2009), y la Ley para Prevenir y Sancionar la Trata de Personas se publicó en el Diario Oficial de la Federación el 27 de noviembre de 2007. Lo anterior ha sido una intensa y gran labor de las(os) legisladoras(es).

33 Cfr. Olamendi Torres, Patricia, Mujeres, familia y ciudadanía, México, UNIFEM, 2008, pp. 113 y 126.

34 Cfr. Carbonell, Miguel (comp.), Instrumentos jurídicos internacionales en materia de no discriminación, México, Consejo Nacional para Prevenir la Discriminación, 2006, pp. 169-177, 225-235, 237-248, y 249-257. 
Respecto de este tema, conforme al artículo 133 de la Constitución, los tratados internacionales signados por el presidente de la República y ratificados por el Senado son Ley Suprema; sin embargo, en otros países se establece claramente que los tratados internacionales se incorporan al ordenamiento jurídico desde su publicación en el Diario o Boletín Oficial del Estado y, además, intervienen ambas cámaras del Congreso o del Parlamento, y no sólo una cámara como es el caso de México. Asimismo, "los tratados internacionales deberán contar con sus propios procedimientos legislativos que deberán regularse en (una) Ley Orgánica y de Funcionamiento del Congreso". ${ }^{35}$ Es de observarse, que falta una legislación más amplia en esta materia. Por lo que cabe pensar en la necesidad de una reforma constitucional a los artículos 73, 74, 76, 89 y 133, orientada a facultar al Congreso de medios para que pueda realizar el diseño de la política exterior del país.

En esta materia, sobresale un hecho sin precedentes: el 10 de junio de 2011 se reforma el artículo 1o. de la Constitución para establecer lo siguiente:

En los Estados Unidos Mexicanos todas las personas gozarán de los derechos humanos reconocidos en esta Constitución y en los tratados internacionales de los que el Estado Mexicano sea parte, así como de las garantías para su protección, cuyo ejercicio no podrá restringirse ni suspenderse, salvo en los casos y bajo las condiciones que esta Constitución establece.

Las normas relativas a los derechos humanos se interpretarán de conformidad con esta Constitución y con los tratados internacionales de la materia favoreciendo en todo tiempo a las personas la protección más amplia.

Todas las autoridades, en el ámbito de sus competencias, tienen la obligación de promover, respetar, proteger y garantizar los derechos humanos de conformidad con los principios de universalidad, interdependencia, indivisibilidad y progresividad. En consecuencia, el Estado deberá prevenir, investigar, sancionar y reparar las violaciones a los derechos humanos, en los términos que establezca la ley... ${ }^{36}$

35 Fix-Fierro, Héctor, Carpizo, Jorge, Valadés, Diego et al., en Barceló Rojas, Daniel (coord.), op. cit., p. 37.

${ }^{36}$ Cfr. Diario Oficial de la Federación, del 10 de junio de 2011, que contiene el Decreto por el que se modifica la denominación del Capítulo I del Título Primero y reforma diversos artículos de la Constitución Política de los Estados Unidos Mexicanos. 


\section{La Ley Orgánica del Congreso General de los Estados Unidos Mexicanos}

De acuerdo con el artículo 70 constitucional, ${ }^{37}$ en 1979 se publicó la Ley Orgánica del Congreso General de los Estados Unidos Mexicanos ${ }^{38} \mathrm{y}$, posteriormente ésta se modificó el 20 de julio de 1994. Sin embargo, y debido al gran número de artículos reformados, lo que sucedió fue propiamente una revisión integral a la ley. Desde entonces hasta septiembre de 1999 no había sido modificada pero, derivado de reformas constitucionales, acuerdos, prácticas parlamentarias y la composición de las cámaras del Congreso, se rebasaron los preceptos de dicha Ley Orgánica y tales circunstancias propiciaron el consenso de los grupos parlamentarios para que los mismos adecuaran $^{39}$ este tipo de fuente del derecho parlamentario en México a las nuevas disposiciones constitucionales, composición de las cámaras e, incluso, a los requerimientos de eficiencia en el trabajo parlamentario.

Por ello, una Ley Orgánica del Congreso fue publicada el 3 de septiembre de 1999, la cual se integra por cinco títulos, que los constituyen 135 artículos y siete transitorios. ${ }^{40}$ En su artículo 3o. señala que el Congreso y las Cámaras que lo componen tendrán la organización y funcionamiento que

37 “Artículo 70. Toda resolución del Congreso tendrá el carácter de ley o decreto. Las leyes o decretos se comunicarán al Ejecutivo firmados por los presidentes de ambas Cámaras y por un secretario de cada una de ellas, y se promulgarán en esta forma: "El Congreso de los Estados Unidos Mexicanos decreta: (texto de la ley o decreto)". El Congreso expedirá la ley que regulará su estructura y funcionamiento internos. La ley determinará, las formas y procedimientos para la agrupación de los diputados, según su afiliación de partido, a efecto de garantizar la libre expresión de las corrientes ideológicas representadas en la Cámara de Diputados. Esta ley no podrá ser vetada ni necesitará de promulgación del Ejecutivo Federal para tener vigencia."

38 Del 25 de mayo de 1979, reformada el 21 diciembre de 1981, que sólo legalizó prácticas y usos parlamentarios que ya se daban. El 20 de julio de 1994 fue publicado el Decreto que la modificó y adicionó, considerado como la "Nueva Ley Orgánica del Congreso General de los Estados Unidos Mexicanos" que simplemente se refiere a la trascripción de las reformas constitucionales que se realizaron antes de 1994, cfr. Ley Orgánica del Congreso General de los Estados Unidos Mexicanos, México, Talleres Gráficos de la Cámara de Diputados, 1990; Barragán, José, “Algunas consideraciones de carácter histórico sobre el régimen interno del Congreso de la Unión”, op. cit., p. 135, y Diario Oficial de la Federación, México, 20 de julio de 1994.

39 Cfr. Chávez, Víctor, "Posibles cambios a la Ley Orgánica del Congreso", El Financiero, México, 18 de diciembre de 1996.

40 Véase para profundizar sobre este tema Pedroza de la Llave, Susana Thalía, "La nueva Ley Orgánica del Congreso General de los Estados Unidos Mexicanos de 1999 y 
establecen la Constitución Política, dicha ley, las reglas de funcionamiento del Congreso General y de la Comisión Permanente, así como los reglamentos y acuerdos que cada una de éstas expida sin la intervención de la otra.

Los principales avances de la Ley Orgánica de 1999 son los siguientes:

1. La desaparición de la Gran Comisión.

2. La creación de una Mesa Directiva con funciones de gobierno.

3. Una mayor duración en el cargo del presidente(a) de la Mesa Directiva.

4. La constitución de la Junta de Coordinación Política.

5. La creación de la Conferencia para la Dirección y Programación de los Trabajos Legislativos.

6. La creación de la Organización Técnica y Administrativa que contempla para la Cámara de Diputados el Servicio Civil de Carrera, mediante el establecimiento de la Secretaría General, la Secretaría de Servicios Parlamentarios, la Secretaría de Servicios Administrativos y Financieros, la Unidad de Capacitación y Formación Permanente de los integrantes de los servicios parlamentarios y administrativos y financieros de la Cámara de Diputados, y la Unidad de Estudios de Finanzas Públicas, y para la Cámara de Senadores también se estableció el Servicio Civil de Carrera, la Secretaría General de Servicios Parlamentarios, la Secretaría General de Servicios Administrativos, y un Centro de Capacitación y Formación Permanente de los integrantes de los servicios públicos del Senado. En octubre de 2008 se creó el denominado "Instituto Belisario Domínguez". ${ }^{41}$

Más adelante, esta Ley Orgánica de 1999 se siguió reformando en diversos años, para ser exactos en 23 ocasiones; por ejemplo, el artículo cuarto transitorio, fracción VI, el 31 de diciembre de 1999; los artículos 39, numeral 2, y 43, numeral 1, el 9 de octubre de 2000; el artículo 40, numeral 4, el 7 de diciembre de 2001; el Título Segundo de la misma, el 29 de septiembre de 2003; los artículos 117 y 118, el 29 de abril de 2004; el artículo 49, el 10 de mayo de 2004; el artículo 3o., el 30 de diciembre de 2004; el numeral 3, del artículo 49, el 3 de marzo de 2005; el numeral

su funcionamiento interno", Boletín Mexicano de Derecho Comparado, México, Nueva Serie, año XXXIII, núm. 99, septiembre-diciembre de 2000, pp. 1303-1318.

${ }^{41} \mathrm{Cfr}$. http://www.senado.gob. $m x /$ index.php? $\mathrm{ver}=\operatorname{sen} \& m n=1 \& s m=6$ y $h t t p: / / w w w$. senado.gob.mx/iilsen/, consultadas el 30 de septiembre de 2010. 
1 del artículo 4 y el numeral 1 del artículo 6, el 8 de marzo de 2005; la fracción XXVIII, recorriéndose las actuales XXVIII y XXIX, pasando a ser XXIX y XXX, respectivamente, del artículo 90, el 30 de diciembre de 2005; el artículo 39, el 23 de enero de 2006; los artículos 26, 34, 36 y 38, el 30 de marzo de 2006; el artículo 40, el 31 de marzo de 2006; se reforman y adicionan diversas disposiciones de la Ley, el 13 de septiembre de 2006; los artículos 39 y 43, el 5 de diciembre de 2006; se establece un artículo transitorio único, el 15 de noviembre de 2007; el artículo 53, el 24 de diciembre de 2007; se adiciona un párrafo al artículo 46, el 21 de abril de 2008; se adicionan diversas disposiciones a la Ley, el 21 de abril de 2008; se reforma el artículo 34, el 26 de junio de 2008; el 5 de marzo de 2009 se publicaron en el Diario Oficial de la Federación las reformas a sus artículos 92, 112 y 113, y el 12 de diciembre de 2011 se adicionó un artículo tercero transitorio respecto de la presidencia de la Mesa Directiva de la Legislatura LXI. ${ }^{42}$

Sin embargo, primero, hace falta incorporar en dicha Ley nuevas figuras, respetando los derechos humanos de los(as) legisladores(as) que pertenecen o no a un grupo parlamentario, esto es, que no se privilegie a los grupos sobre los(as) legisladores(as) de ambas Cámaras; que los(as) parlamentarios(as) cuenten con facultades propias y con relación a la ciudadanía; que los procedimientos estén debidamente regulados; respetar los derechos de las minorías; la igualdad de los(as) parlamentarios(as), entre otros. Incluso, existe una propuesta para que dicha Ley sea denominada como "Ley Orgánica y de Funcionamiento del Congreso"43 o se expedida una nueva Ley. ${ }^{44}$ Segundo, se observa que las leyes Orgánicas están reservadas para determinada materia $y$, en algunos países, se requiere de una mayoría calificada para aprobarlas y, en otros casos, hasta referéndum; ${ }^{45}$ sin embargo, tampoco éste no es el caso de México, ya que sólo se solicita que se cumpla con el quórum de reunión y luego es necesario obtener el

42 Cfr. http://www.diputados.gob.mx/LeyesBiblio/ref/locg.htm, consultada el 3 de marzo de 2009, el 19 de enero y el 30 de septiembre de 2010, y el 12 de abril de 2012.

43 Fix-Fierro, Héctor, Carpizo, Jorge, Valadés, Diego et al., en Barceló Rojas, Daniel (coord.), op. cit., pp. 35 y 37.

44 Cfr. Gaceta Parlamentaria, Cámara de Diputados, núm. 2987-III, martes 13 de abril de 2010, Iniciativa que expide la Ley del Congreso General de los Estados Unidos Mexicanos, y el Reglamento para el Gobierno Interior de la Cámara de Diputados, a cargo de la diputada Josefina Vázquez Mota, del Grupo Parlamentario del PAN.

45 Cfr. Aguiar de Luque, Luis y Pérez Tremps, Pablo (dirs.), op. cit., pp. 75 y 76, y 78. 
voto de la mayoría de los(as) presentes, por lo que es prácticamente sencillo modificar dicha Ley en una situación en la que el Congreso esté integrado por mayorías, dejando de lado a las minorías.

Independientemente de la Ley Orgánica del Congreso General de los Estados Unidos Mexicanos, también consideramos como fuente del derecho parlamentario mexicano las Leyes de Ingresos de la Federación para el ejercicio fiscal correspondiente; la Ley General de Deuda Pública, del 31 de diciembre de 1976; la Ley Reglamentaria de la Fracción V del Artículo 76 de la Constitución Política de los Estados Unidos Mexicanos, del 29 de diciembre de 1978; la Ley Reglamentaria de la Fracción XVIII del Artículo 73 Constitucional en lo que se refiere a la facultad del Congreso para dictar reglas para determinar el valor relativo a la moneda extranjera, del 27 de diciembre de 1982; la Ley Federal de Responsabilidades de los Servidores Públicos, del 31 de diciembre de 1982; la Ley de Planeación, del 5 de enero de 1983; la Ley sobre la Celebración de Tratados, del 2 de enero de 1992; la Ley de Amnistía, del 28 de septiembre de 1978; la Ley de Amnistía (citación en Chiapas), del 22 de enero de 1994; la Ley Federal de Procedimiento Administrativo, del 4 de agosto de 1994; la Ley Federal de Responsabilidades Administrativas de los Servidores Públicos, del 13 de marzo de 2002; la Ley Federal de Transparencia y Acceso a la Información Pública Gubernamental, del 11 de junio de 2002; la Ley Federal de Presupuesto y Responsabilidad Hacendaria, del 30 de marzo de 2006; la Ley Reglamentaria de la Fracción VI del Articulo 76 de la Constitución Política de los Estados Unidos Mexicanos, del 31 de agosto de 2007; la Ley de Fiscalización y Rendición de Cuentas de la Federación, del 29 de mayo de 2009, entre otras, como el Código Federal de Instituciones y Procedimientos Electorales del 14 de enero de 2008, del cual algunos artículos se declararon inválidos por sentencia de la SCJN publicada el 3 de octubre de 2008 en el Diario Oficial de la Federación.

Todos los anteriores son fuente del derecho parlamentario en México; por ejemplo, el Cofipe en lo relativo a la integración del Poder Legislativo; requisitos de elegibilidad para ser diputado(a) o senador(a), y representación proporcional para la integración de las cámaras, por ejemplo.

\section{El Reglamento del Congreso}

La denominación real del Reglamento del Congreso en nuestro país es el "Reglamento para el Gobierno Interior del Congreso General de los Estados Unidos Mexicanos", del 20 de marzo de 1934, reformado el 21 de 
noviembre de ese mismo año; el 31 de diciembre de 1935; el 16 de octubre y el 1o. de noviembre de 1937; el 27 de enero de 1940; el 21 de diciembre de 1957; el 31 de diciembre de 1963; el 21 de octubre de 1966, el 20 de enero y el 11 de diciembre de 1975; el 27 de noviembre de 1981; el 4 de junio de $2010 \mathrm{y}$, para ser exactos ha sufrido reformas en 13 ocasiones. ${ }^{46}$ Respecto de las últimas, que también las consideramos como reformas, con la publicación del Reglamento del Senado de la República (4 de junio de 2010), en donde a partir del 1 de septiembre de 2010 dejaron de ser aplicables, en cuanto se refiere al Senado, las disposiciones relativas del Reglamento para el Gobierno Interior del Congreso General de los Estados Unidos Mexicanos, conforme al artículo Segundo Transitorio del Decreto de fecha 14 de diciembre de 2004, publicado en el Diario Oficial de la Federación el 30 de diciembre del mismo año, por el que se reformó el artículo 3, numeral 1, de la Ley Orgánica del Congreso General de los Estados Unidos Mexicanos. Asimismo, a partir del día siguiente al 24 de diciembre de 2010, con la publicación del Reglamento de la Cámara de Diputados, en su artículo tercero transitorio quedan sin efecto para dicha cámara, las disposiciones contenidas en el Reglamento para el Gobierno Interior del Congreso General de los Estados Unidos Mexicanos publicado en el Diario Oficial de la Federación el 20 de marzo de 1934 y sus reformas.

En este sentido, el reglamento sigue siendo una fuente del derecho parlamentario en México, el cual desarrolla, amplía las disposiciones constitucionales relativas a la actividad parlamentaria y regula los aspectos no considerados por la Constitución, por la Ley Orgánica y, por cualquier otra disposición, relativa al Congreso General y a su Comisión Permanente; por ejemplo, así lo reitera el artículo noveno transitorio del Reglamento de la Cámara de Diputados.

Asimismo, y en cuanto al Reglamento del Congreso, tenemos que la "reserva de la ley con relación a determinada materia no impide la colaboración del reglamento en el desarrollo normativo de la misma, siempre que la utilización de éste resulte indispensable por motivos técnicos o para optimizar el cumplimiento de las finalidades propuestas por la Constitución o por la propia ley". ${ }^{47}$

46 Cfr. http://www.diputados.gob.mx/LeyesBiblio/ref/rgic.htm, consultada el 3 de marzo de 2009, 19 de enero de 2010 y 12 de abril de 2012. A ese respecto, sólo en 13 ocasiones se ha reformado, esto muestra que, al parecer, dicho reglamento no ha tenido la importancia suficiente.

47 Aguiar de Luque, Luis y Pérez Tremps, Pablo (dirs.), op. cit., p. 89. 
A pesar de diversos intentos ${ }^{48}$ aislados por parte de algunos congresistas o parlamentarios, no se ejerció durante muchos años la facultad de legislar que tiene cada una de las Cámaras del Congreso en materia de Reglamentos, ${ }^{49}$ en el sentido que cada una de las Cámaras está facultada para tener su propio Reglamento conforme a lo que señala expresamente el artículo 77 de la Constitución. ${ }^{50}$ Situación que cambia hasta 2010. En relación con el Senado, el 4 de junio de ese año se publicó en el Diario Oficial de la Federación el Reglamento del Senado de la República. Asimismo, el 24 de diciembre de ese año se publica, en el Diario Oficial de la Federación, el Reglamento de la Cámara de Diputados. Temas que se abordarán en rubros específicos de este trabajo. En este mismo orden de ideas, el artículo 30. de la Ley Orgánica del Congreso señala que el Congreso y las cámaras que lo componen tendrán la organización y funcionamiento que establecen la Constitución, la ley, las reglas de funcionamiento del Congreso General y de la Comisión Permanente, así como los reglamentos y acuerdos que cada una de éstas expida sin la intervención de la otra.

En nuestro país, a dicho reglamento no se le dio la importancia que tiene $\mathrm{y}$, mucho menos, se había expedido uno para cada una de las cáma-

48 Desde 1996 se planteó presentar la iniciativa que reformaba la LOCG. Cfr. Chávez, Víctor, op. cit.

49 El 22 de agosto de 2001 el diputado Ricardo Francisco García Cervantes, entonces presidente de la Cámara de Diputados, en la sesión de la Comisión Permanente presentó su "Iniciativa con Proyecto de Decreto por el que se crea la Ley del Congreso de la Unión y se abroga la Ley Orgánica del Congreso General de los Estados Unidos Mexicanos y el Reglamento para el Gobierno Interior del Congreso General de los Estados Unidos Mexicanos" en la que se pretende incluir todos los aspectos de ambos ordenamientos en uno solo.

50 “Articulo 77. Cada una de las Cámaras puede, sin intervención de la otra:

I. Dictar resoluciones económicas relativas a su régimen interior.

II. Comunicarse en la Cámara colegisladora y con el Ejecutivo de la Unión, por medio de comisiones de su seno.

III. Nombrar los empleados de su secretaría y hacer el Reglamento Interior de la misma.

IV. Expedir convocatoria, dentro del término de 30 días a partir de que ocurra la vacante, para elecciones extraordinarias que deberán celebrarse dentro de los 90 días siguientes, con el fin de cubrir las vacantes de sus miembros a que se refiere el artículo 63 de esta Constitución, en el caso de vacantes de diputados y senadores del Congreso de la Unión por el principio de mayoría relativa, salvo que la vacante ocurra dentro del año final del ejercicio del legislador correspondiente". 
ras a pesar de considerarse que el reglamento de cualquier asamblea es la fuente por excelencia de la actividad parlamentaria. ${ }^{51}$

En este sentido, únicamente se tenía un reglamento para todo el Congreso, ${ }^{52}$ considerado obsoleto, ${ }^{53}$ pero se presentaron algunas iniciativas con proyecto de Reglamento para la Cámara de Senadores, las cuales son las siguientes:

1. El 14 de diciembre de 2001, del senador César Jáuregui Robles del Partido Acción Nacional.

2. El 14 de diciembre de 2001, de los senadores Lidia Madero, Mariano González Zarur, Raymundo Cárdenas Hernández y Gerardo Buganza Salmerón, iniciativa plural.

3. El 8 de diciembre de 2005, del senador Federico Ling Altamirano del Partido Acción Nacional.

4. El 24 de octubre de 2006, del senador Héctor Pérez Plazota del Partido Acción Nacional.

5. El 7 de diciembre de 2006, del senador Pablo Gómez Álvarez del Partido de la Revolución Democrática.

Finalmente, en el Senado de la República se han analizado dichas iniciativas por un grupo de trabajo y se elaboró un proyecto de Reglamento que se sujetó a revisión, fue aprobado y se publicó el 4 de junio de 2010, entrando en vigor el 1o. de septiembre de ese año, y lo mismo ocurrió respecto a la Cámara de Diputados, en donde se dieron avances, ${ }^{54}$ pero aprobándose el

51 Cfr. Muñoz Q., Hugo Alfonso, "La jurisdicción constitucional y el derecho parlamentario", en Bertolini, Anarella y Fernández, Hubert (eds.), La jurisdicción constitucional y su influencia en el Estado de derecho, San José, Costa Rica, Editorial Universidad Estatal a Distancia, 1999, p. 51.

52 En este sentido, existe una investigación previa, tratando de impulsar la existencia de mayor normatividad en esta materia, para ello $c f r$. Pedroza de la Llave, Susana Thalía, "Las fuentes del derecho parlamentario en México", Documento de trabajo, México, núm. 138, diciembre de 2009, pp. 1-21.

53 Consúltese Ramírez Marín, Juan, "Del Reglamento para el Gobierno Interior del Congreso General de los Estados Unidos Mexicanos", Quórum Legislativo, México, núm. 90 , julio-septiembre de 2007 , pp. 1-48, quien realiza un estudio muy completo sobre este reglamento.

54 Cfr. Gaceta Parlamentaria, Cámara de Diputados, núm. 2987-III, martes 13 de abril de 2010, Iniciativa que expide la Ley del Congreso General de los Estados Unidos Mexicanos, y el Reglamento para el Gobierno Interior de la Cámara de Diputados, a cargo de la diputada Josefina Vázquez Mota, del Grupo Parlamentario del PAN. 
15 de diciembre de dicho año y publicado el día 24 del mismo mes y año, y que entró en vigor el 1o. de enero de 2011.

Respecto al tema del Reglamento para cada una de las cámaras, de lo que se consideró muy conveniente, como ya se ha hecho, en el Reglamento de la Asamblea Legislativa del Distrito Federal, es la incorporación que se podrán efectuar foros y consultas legislativas sobre los asuntos a su cargo, y temas relativos a la atención, orientación y quejas ciudadanas, así como los puntos o requisitos que tendrán que abordar las leyes y los decretos en materia de técnica legislativa; por ejemplo, que se redacten los preceptos jurídicos de forma bien estructurada, que cumplan con el principio de seguridad jurídica y los principios generales del derecho, que contengan la justificación o exposición de motivos de la norma, que su redacción sea de manera clara, breve, sencilla y accesible para las personas a las que está destinada la norma, que su inserción sea armónica con relación a otros ordenamientos y que tome en cuenta el ámbito de validez.

Incluso, se consideró necesario establecer la participación de la ciudadanía, de las empresas, o quienes tengan interés en colaborar en la discusión de alguna iniciativa, así como regular el cabildeo y la iniciativa legislativa ciudadana. ${ }^{55}$

\section{El Reglamento del Senado de la República}

Este reglamento fue publicado en el Diario Oficial de la Federación el 4 de junio de 2010, entró en vigor el 1o. de septiembre de ese mismo año y consta de 312 artículos y cuatro transitorios. Es novedoso al establecer la igualdad entre mujeres y hombres, particularmente al señalar que por presidente o por senador se entiende la presidenta o el presidente, y la senadora y el senador, respectivamente. Incluye lo relativo al sistema automatizado de registro, asistencia, votación y audio que existe en dicha cámara. Asimismo, de la lectura de este reglamento se desprende que se redacta en tiempo presente. Se deja claro desde qué momento los senadores tienen fuero constitucional, es decir, desde el momento en que éstos protestan el cargo. De igual manera, precisa ante quiénes pueden iniciar leyes y decretos, los trámites para solicitar licencia, las inasistencias y quién es el órgano competente para conocer sobre la responsabilidad administrativa

55 Cfr. Fix-Fierro, Héctor, Carpizo, Jorge, Valadés, Diego et al., en Barceló Rojas, Daniel (coord.), op. cit., pp. 36 y 37. 
en que puedan incurrir los senadores (Mesa Directiva y Pleno). También fija la hora en que inician las sesiones y cuál es el tiempo de su duración. A grandes rasgos, este nuevo reglamento contiene una legislación muy amplia sobre cómo se desarrolla el orden del día, el debate, las votaciones, las mociones, los trabajos en comisiones y comités, la organización de los Grupos Parlamentarios, el procedimiento legislativo en el que destaca que se plasman los elementos de técnica legislativa a seguir, la posibilidad de convocar a audiencias públicas, la emisión de votos particulares, los plazos para los dictámenes, y todo lo relativo a los procedimientos que tiene la Cámara de Senadores para realizar sus facultades y obligaciones (análisis de la política exterior; tratados internacionales; nombramientos y remociones; desaparición de poderes; constituirse como jurado de sentencia; remoción y designación del jefe de gobierno del Distrito Federal; límites entre las entidades federativas; los informes, comparecencias y las preguntas parlamentarias a diversos servidores públicos; ceremonial y protocolo; transparencia y acceso a la información pública, entre otros). Asimismo, recoge todo lo que ya está establecido en la Constitución o en la Ley Orgánica del Congreso General respecto de la Mesa Directiva, la Junta de Coordinación Política, el Pleno, los tipos de Comisiones y sus Juntas Directivas, los Comités, los Grupos Parlamentarios, así como sus órganos administrativos y técnicos.

\section{El Reglamento de la Cámara de Diputados}

Este reglamento fue publicado en el Diario Oficial de la Federación el 24 de diciembre de 2010, entró en vigor el 1o. de enero de 2011 y consta de 285 artículos y décimo trece transitorios. En sus primeros artículos determina que tiene por objeto normar la actividad parlamentaria de la Cámara de Diputados, así como establecer los procedimientos internos que hagan eficiente su estructura y funcionamiento. Es novedoso al establecer ya no sólo el término de diputado, sino de diputada. Tiene un artículo específico dedicado a varias voces y sus significados; por ejemplo, legislatura es el periodo durante el cual la cámara, que será de tres años, contados a partir de su instalación, así como las definiciones de mayoría absoluta, calificada y simple, año legislativo, entre otros. Desarrolla ampliamente cuáles son las obligaciones de los diputados y diputadas, así como los casos en que pueden solicitar licencia. Varias de las normas de este reglamento se refieren a promover la equidad de género en los órganos que constituyen a 
dicha cámara. Se señalan con precisión los días de la semana y horas que sesionará la cámara. Asimismo, abarca la normatividad relativa a los procedimientos del Pleno, de las Comisiones y Subcomisiones. Sobresale ya la regulación de los elementos que debe contener una iniciativa de ley o decreto y los de un dictamen, de un proyecto, es decir, contempla la llamada técnica legislativa; define los acuerdos y puntos de acuerdos parlamentarios, así como la posibilidad de emitir votos particulares. De igual manera, contempla como serán las discusiones en el Pleno y sus tiempos; las mociones; las comparecencias; las preguntas parlamentarias a los servidores públicos contemplados en el artículo 93 constitucional; las peticiones; lo relativo a las comisiones, comités, subcomisiones, grupos de trabajo, y los procedimientos que se llevan a cabo en éstos, así como las normas que se seguirán para la discusión del Presupuesto de Egresos de la Federación, de la Cuenta Pública, y de las reformas a la Constitución Política. Finalmente, y como tema novedoso, contempla los instrumentos internos de comunicación del trabajo legislativo, como son el Diario de los Debates, las versiones estenográficas, la Gaceta Parlamentaria, los servicios de información en Internet, la relación con los medios de comunicación y define al Cabildeo y su registro, y a la Diplomacia parlamentaria en la cámara.

\section{El Reglamento del Canal de Televisión del Congreso General de los Estados Unidos Mexicanos}

El Canal de Televisión del Congreso en México es muy novedoso, no muchos países lo tienen establecido, y el cual se encuentra regulado por un Reglamento específico que surge, sin claridad, de la facultad que tiene cada una de las Cámaras del Congreso para emitir su "Reglamento" (artículo 77 de la Constitución). En este sentido, para tener mayor claridad en la materia, sería conveniente una reforma a este artículo 77 constitucional, para que las cámaras puedan emitir "reglamentos" de diversa índole respecto a su gobierno interior, como es el Canal del Congreso. De tal forma, el artículo 77 podría tener más claridad en materia de reglamentos.

Asimismo, el Canal del Congreso tampoco tiene su fundamento en el artículo 3o. de la Ley Orgánica del Congreso que señala que el Congreso y las cámaras que lo componen tendrán la organización y funcionamiento que establecen la Constitución, la ley, las reglas de funcionamiento del Congreso General y de la Comisión Permanente, así como los "reglamentos" y 
"acuerdos" que cada una de éstas expida sin la intervención de la otra. Por ello, consideramos al Reglamento del Canal de Televisión del Congreso General de los Estados Unidos Mexicanos del 18 de mayo de 2005 como una fuente formal del derecho parlamentario, pero sin una clara normatividad constitucional en México.

$\mathrm{Su}$ origen data del 13 de junio de 2000, fecha en que se dio el Acuerdo de la Comisión Bicamaral del Canal de Televisión del Congreso, mediante el que se aprobó el Proyecto de Reglamento del Canal de Televisión. ${ }^{56} \mathrm{Su}$ propósito es reseñar y difundir la actividad legislativa y parlamentaria que corresponda a las cámaras del Congreso y de la Comisión Permanente, así como contribuir a informar, analizar y discutir pública y ampliamente la situación de los problemas de la realidad nacional vinculados con la actividad legislativa.

Dicho canal de televisión es un órgano del Poder Legislativo y es de interés público al propiciar el derecho a la información, la libertad de expresión, el fomento de la democracia, entre otros. Entre sus principios y objetivos destacan el colocar en el espacio público los intereses de la nación en el marco de la pluralidad democrática y la tolerancia; fomentar la difusión del análisis, discusión y debate de los problemas nacionales para fortalecer la opinión pública; contribuir al fortalecimiento educativo y cultural, así como fomentar el desarrollo de la cultura cívica y política en la sociedad; también busca promover los valores humanos y sociales garantizados por la Constitución; fomentar un debate político ciudadano permanente sobre los temas que se aborden en el Congreso; coadyuvar a difundir el pensamiento, la cultura, las ciencias y las artes en sus variadas y plurales manifestaciones, entre otros.

La conducción del canal está a cargo de la Comisión Bicamaral y de la Dirección General. La primera será presidida por el o la diputada o senador(a) electo(a) de manera directa por los miembros que la constituyan, la misma será rotatoria cada 12 meses entre los grupos parlamentarios representados en la Comisión y alternada entre ambas cámaras.

56 Cfr. Acuerdo de la Comisión Bicamaral del Canal de Televisión del Congreso General de los Estados Unidos Mexicanos por el que se aprueba el Proyecto de Reglamento del Canal de Televisión del propio Congreso, México, Cámara de Diputados, del 13 de junio de 2000. La Iniciativa con Proyecto de Decreto por el que se expide el Reglamento del Canal de Televisión del Congreso de la Unión, se presentó ante el pleno de la Cámara de Senadores el 19 de abril de 2001, y fue turnada para su dictamen a la Comisión de Comunicaciones y Transportes y a la Comisión de Estudios Legislativos. 
A la Comisión Bicamaral le corresponde emitir las bases de la convocatoria para el procedimiento de la designación del titular de la Dirección General de dicho canal que durará en su cargo cuatro años y podrá ser reelecta por un periodo igual. Entre los requisitos para ocupar el cargo de director(a) general se encuentra contar con amplia experiencia en el ramo de los medios de comunicación. De igual forma, la Comisión Bicameral puede remover de su cargo a dicho(a) director(a) general.

En relación con lo anterior, el Canal del Congreso es o puede pretender ser una televisión pública en todos los sentidos. Sin embargo, en esta materia lo principal sería que dicho canal sea considerado totalmente como un canal de televisión pública y que tenga cobertura nacional, ${ }^{57}$ ya que actualmente para verlo se requiere tener contratada televisión por cable, aunque la finalidad será por su importancia y a corto plazo ser un canal público y nacional.

\section{El Estatuto de la Organización Técnica y Administrativa $y$ del Servicio de Carrera de la Cámara de Diputados}

Por otra parte, el servicio de carrera de la Cámara de Diputados no se encuentra regulado por un Reglamento específico, sino por un Estatuto que surge, sin claridad, de la facultad que tiene cada una de las cámaras del Congreso para emitir su "Reglamento" (artículo 77 de la Constitución). De tal forma, nuevamente el artículo 77 podría tener más claridad en la materia. Asimismo, tampoco tiene su fundamento en el artículo 3o. de la Ley Orgánica del Congreso que señala que el Congreso y las Cámaras que lo componen tendrán la organización y funcionamiento que establecen la Constitución, la ley, las reglas de funcionamiento del Congreso General y de la Comisión Permanente, así como los "reglamentos" y "acuerdos" que cada una de éstas expida sin la intervención de la otra. Sin embargo, hace referencia a este Estatuto la Ley Orgánica en sus artículos 20, 34, 38, 49, 55, 56 y 57. Por ello, consideramos al Estatuto de la Organización Técnica y Administrativa y del Servicio de Carrera de la Cámara de Diputados como una fuente formal del derecho parlamentario, pero sin una clara normatividad constitucional en México.

57 Cfr. Pedroza de la Llave, Susana Thalía, "Concentración de medios y pluralismo: el marco jurídico del canal de televisión del Congreso mexicano", en Carpizo, Jorge y Carbonell, Miguel (coords.), Derecho a la información y derechos humanos; estudios en homenaje al maestro Mario de la Cueva, México, UNAM, 2000, pp. 309-325. 
El Servicio de Carrera consiste en que las cámaras del Congreso cuenten con asesores(as) institucionales - llamados en España Letrados de las Cortes - , los cuales deben desarrollar sus funciones bajo los principios de legalidad, objetividad, imparcialidad, rapidez, eficacia y permanencia. A este personal le corresponde aportar la información, documentos, datos, estudios y análisis para que el o la legisladora pueda asumir su decisión en cada asunto. Son órganos técnicos de apoyo, sirven para ayudar a los(as) legisladores(as). ${ }^{58}$

E1 22 de mayo de 2000 se publicó en el Diario Oficial de la Federación el Estatuto de la Organización Técnica y Administrativa y Servicio de Carrera de la Cámara de Diputados, que regula el Servicio Civil de Carrera. $\mathrm{Su}$ objeto es establecer la organización y funcionamiento de la Secretaría General; de las secretarías de Servicios Parlamentarios y de Servicios Administrativos y Financieros; de la Coordinación de Comunicación Social; de los centros de estudios de las Finanzas Públicas; de Derecho e Investigaciones Parlamentarias; y de Estudios Sociales y de Opinión Pública; lo relativo al Servicio de Carrera de la Cámara de Diputados en los términos de la Ley Orgánica del Congreso y de los ordenamientos, políticas y lineamientos respectivos, y la organización y funcionamiento de la Contraloría Interna. En dicho estatuto se enumeran los órganos con los que cuenta la Cámara de Diputados para el mejor cumplimiento de sus funciones constitucionales y la atención eficiente de sus necesidades administrativas y financieras, las cuales son las siguientes:

\section{La Secretaría General.}

II. La Secretaría de Servicios Parlamentarios, a la cual están adscritas la Dirección de Asistencia a la Presidencia de la Mesa Directiva; la Dirección de Servicios a la Sesión; la Dirección de Comisiones y Comités; la Dirección del Diario de los Debates; la Dirección del Archivo; la Dirección de Bibliotecas; el Centro de Estudios de las Finanzas Públicas; el Centro de Estudios de Derecho e Investigaciones Parlamentarias, y el Centro de Estudios Sociales y de Opinión Pública.

III. La Secretaría de Servicios Administrativos y Financieros, en la cual están adscritas: la Dirección de Recursos Humanos, la Dirección de

58 Cfr. Mora-Donatto, Cecilia, "Urgente rediseñar el servicio de carrera del Congreso mexicano", Cuestiones Constitucionales. Revista Mexicana de Derecho Constitucional, México, núm. 19, julio-diciembre de 2008, pp. 173-175, y Fix-Fierro, Héctor, Carpizo, Jorge, Valadés, Diego et al., en Barceló Rojas, Daniel (coord.), op. cit., pp. 38 y 39. 
Tesorería, la Dirección de Recursos Materiales, la Dirección de Servicios Generales y de Informática, la Dirección Jurídica, y la Dirección de Seguridad, Dirección de Servicios Médicos y de Atención a Diputados. IV. La Coordinación de Comunicación Social.

V. La Unidad de Capacitación y Formación Permanente.

En cuanto a este tema, relativo al Servicio Civil de Carrera, primero, es que el Estatuto de la Organización Técnica y Administrativa y del Servicio de Carrera de la Cámara de Diputados casi no hace referencia al mismo, sino que aborda principalmente los órganos con los que cuenta la Cámara de Diputados y es hasta su título tercero que se refiere a éste. Segundo, lo más preocupante es que no funcione el Servicio Civil de Carrera en dicha Cámara y es muy necesario que éste opere, ya que de acuerdo a diversos testimonios del personal en dicha cámara, por un Acuerdo Parlamentario este Servicio no ha funcionado, ${ }^{59}$ no está en funcionamiento, por ello cuando llegue a estarlo es importante que el mayor número de servidores(as) públicos(as) de la Cámara de Diputados pertenezcan a dicho servicio y que los concursos no se declaren desiertos y que en la etapa final del concurso no haya una entrevista, ya que en esta última se puede perder la objetividad. Lo anterior para lograr el buen funcionamiento de este sistema y que sea en beneficio de los(as) trabajadores(as) y de la propia institución.

\section{El Estatuto del Servicio Civil de Carrera del Senado}

El servicio de carrera de la Cámara de Senadores no se encuentra regulado por un Reglamento específico, sino por un Estatuto que surge, sin claridad, de la facultad que tiene cada una de las cámaras del Congreso para emitir su "Reglamento" (artículo 77 de la Constitución). De tal forma, nuevamente

59 A ese respecto, se publicó en la Gaceta Parlamentaria, el 20 de diciembre de 2005, el Acuerdo titulado "DE LA CONFERENCIA PARA LA DIRECCIÓN Y PROGRAMACIÓN DE LOS TRABAJOS LEGISLATIVOS POR EL QUE SE AUTORIZA LA REINGENIERÍA DE LA ESTRUCTURA organizacional de la Secretaría General, Secretaría de Servicios Parlamentarios y Secretaría de SERVicios Administrativos y Financieros", en el que en su acuerdo cuarto determina "En su oportunidad, se promoverá la presentación de un nuevo Estatuto de la Organización Técnica y Administrativa y del Servicio de Carrera de la Cámara de Diputados...", cfr. http://gaceta.diputados.gob.mx/Gaceta/59/2005/ dic/20051220.html, consultada el 13 de abril de 2010. 
el artículo 77 podría tener más claridad en la materia. Asimismo, tampoco tiene su fundamento en el artículo 3o. de la Ley Orgánica del Congreso que señala que el Congreso y las Cámaras que lo componen tendrán la organización y funcionamiento que establecen la Constitución, la ley, las reglas de funcionamiento del Congreso General y de la Comisión Permanente, así como los "reglamentos" y "acuerdos" que cada una de éstas expida sin la intervención de la otra. Sin embargo, hace referencia a este Estatuto la Ley Orgánica en su artículo 114, pero sin una clara normatividad constitucional.

El Estatuto fue aprobado por el Pleno, el 7 noviembre de 2002, y publicado en el Diario Oficial de la Federación el 22 del mismo mes y año. Se integra por seis títulos. El primero se refiere a la "Organización del Servicio Civil"; el segundo a la "Operación del Servicio Civil"; el tercero a la "Capacitación y formación permanente"; el cuarto a "Las remuneraciones y estímulos para el personal de carrera del Servicio Civil"; el quinto a "Los derechos, las obligaciones y sanciones de los miembros del Servicio Civil", y el sexto se titula "Del procedimiento administrativo para la aplicación de sanciones". ${ }^{60}$

Al igual que lo señalado respecto a la Cámara de Diputados, lo ideal es que el mayor número de servidores(as) públicos(as) de la Cámara de Senadores pertenezcan a dicho servicio, que los concursos no se declaren desiertos y que en la etapa final del concurso no haya una entrevista. Aquí es necesario precisar que, de acuerdo a diversos testimonios de personas pertenecientes a dicho servicio en la Cámara de Senadores, todos mencionan que está funcionando y funciona bien. Como se puede observar, esta normatividad si contempla en su totalidad al Servicio Civil de Carrera.

\section{El Estatuto para los Servicios Parlamentarios,} Administrativos y Técnicos del Senado de la República

Recientemente, el 27 de diciembre de 2011, se publicó el Estatuto para los Servicios parlamentarios, administrativos y técnicos del Senado de la República, que entró en vigor el 1o. de febrero de 2012, y que tiene por objeto establecer la estructura, las relaciones de mando, coordinación y supervisión, así como la adscripción y funciones de las dependencias y unidades

60 Para mayor información consúltese http://www.senado.gob.mx/admon/estatuto.html. 
de apoyo que dirigen y prestan los servicios parlamentarios, administrativos y técnicos. ${ }^{61}$

\section{Reglamentos interiores de las comisiones legislativas y otros reglamentos}

Dentro de las cámaras; por ejemplo, las comisiones pueden tener reglamentos que organicen su funcionamiento interno como el Reglamento Interior del Instituto Belisario Domínguez del Senado de la República, u otros Reglamentos en general: Reglamento de la Medalla al Mérito Cívico "Eduardo Neri, Legisladores de 1913"; Reglamento de Transparencia, Acceso a la Información Pública y Protección de Datos Personales de la Cámara de Diputados, y el Reglamento Interior de la Unidad de Evaluación y Control de la Comisión de Vigilancia de la Cámara de Diputados. Éstos también constituyen una fuente del derecho parlamentario. En esta materia, sólo algunas legislaturas de las entidades federativas cuentan con una normatividad de tal naturaleza; por ejemplo, la Asamblea Legislativa del Distrito Federal. Sin embargo, éstos surgen, sin claridad, de la facultad que tiene cada una de las cámaras del Congreso para emitir su "reglamento" (artículo 77 de la Constitución).

\section{Los acuerdos parlamentarios}

y los puntos de acuerdo

El artículo 77, fracción I, de la Constitución establece que cada una de las cámaras puede, sin intervención de la otra, dictar resoluciones económicas relativas a su régimen interior. De igual manera, el artículo 3o. de la Ley Orgánica del Congreso señala que éste y las cámaras que lo componen tendrán la organización y funcionamiento que establecen la Constitución, la ley, las reglas de funcionamiento del Congreso y de la Comisión Permanente, así como los reglamentos y "acuerdos" que cada una de éstas expida sin la intervención de la otra. Por ello, los acuerdos y puntos de acuerdos parlamentarios están plasmados, en cierta forma, en la norma constitucional y de manera precisa en la Ley Orgánica del Congreso.

${ }^{61}$ Cfr. http://www.diputados.gob.mx/LeyesBiblio/marjur/marco/senado/Senado_ estatuto_27dic11.pdf, consultada el 12 de abril de 2012. 
Es así como los acuerdos parlamentarios son considerados como normas creadas para regular algún procedimiento, en particular, al interior de cada una de las cámaras. Por medio de dichos acuerdos se permite la colaboración y la convivencia pacífica en el desarrollo de las sesiones.

En la actualidad los acuerdos tienden a aumentar en número e importancia. Sin embargo, éstos no deben regular situaciones al exterior, y no sobrepasar a la ley y a la Constitución. Asimismo, "han sido la vía preferida de las cámaras para innovar su ordenamiento; sobre todo a partir de la LVII Legislatura cuya pluralidad así lo exigió, con el enorme riesgo que implica y la alta dosis de inseguridad jurídica que acarrea tal situación". ${ }^{62}$

Aun cuando los acuerdos son muy empleados, recientemente se considera que no existe una regulación precisa de los mismos, por ello se produce su empleo indiscriminado y se pierde el rigor conceptual y jurídico, ${ }^{63}$ lo cual trae aparejado una gran problemática, porque su uso es indiscriminado y no se entiende para qué son en específico y se emplean para cualquier circunstancia y sin tener un objetivo claro y preciso.

Hasta hace relativamente algunos años atrás, dentro del marco jurídico de la Cámara de Diputados, se encontraban varios acuerdos; por ejemplo, Acuerdo Parlamentario Relativo a las Sesiones, Integración del Orden del Día, los Debates y las Votaciones de la Cámara de Diputados; Acuerdo Parlamentario Relativo a la Organización y Reuniones de las Comisiones y Comités de la Cámara de Diputados; Acuerdo Parlamentario para la Creación de la Unidad de Estudios de Finanzas Públicas de la H. Cámara de Diputados; Acuerdo Parlamentario Relativo a la Comisión de Jurisdicción y a la Sección Instructora de la H. Cámara de Diputados; Acuerdo Relativo a los Apoyos que han de Recibir los Diputados sin Partido; Acuerdo que establece los lineamientos que se observarán para acreditar las asistencias de los diputados a las sesiones plenarias, así como para la debida justificación de los retardos e inasistencias a las mismas; Acuerdo por el que se determina que las directivas de las comisiones informen a la Conferencia para la Dirección y Programación de los Trabajos Legislativos sobre la comparecencia de miembros del gabinete legal y ampliado del Gobierno de la República; Acuerdo Parlamentario por el que se establecen las bases para el desarrollo de

62 Fix-Fierro, Héctor, Carpizo, Jorge, Valadés, Diego et al., en Barceló Rojas, Daniel (coord.), op. cit., p. 33.

63 Cfr. Roldán Xopa, José, El sistema de fuentes del Senado, México, Senado de la República-ITAM-Miguel Ángel Porrúa, 2003, p. 85. 
las comparecencias de funcionarios del Ejecutivo Federal, ante la Cámara de Diputados, para el análisis del I Informe de Gobierno del Presidente de la República, Administración 2000-2006, y Acuerdo Parlamentario relativo a la Integración del Orden del Día, las Discusiones y las Votaciones ${ }^{64}$ En esta materia, algunas personas estudiosas del tema se preguntan si con la Ley Orgánica del Congreso de 1999 los acuerdos parlamentarios de 1997 ya no tienen validez. En este sentido, nosotros consideramos que es necesario aplicar en estos casos lo que dispone el artículo 72 constitucional, punto $\mathrm{F}$, al señalar que en la interpretación, reforma o derogación de las leyes o decretos, se observarán los mismos trámites establecidos para su formación, entonces sí serán válidos siempre y cuando el acuerdo parlamentario no contradiga a la Ley Orgánica que tiene un rango superior jerárquico o que éstos hayan no hayan sido abrogados o derogados por otros acuerdos o por una norma superior como es el caso del Reglamento de la Cámara de Diputados, del 24 de diciembre de 2010, que entró en vigor el 1o. de enero de 2011 y que abrogó acuerdos específicos del 22 junio de 2005; dos del 27 de septiembre de 2006; del 28 de febrero de 2007; 12 y 28 de octubre de 2006; 18 de septiembre de 2009, y del 8 de diciembre de 2009. De igual manera, si el acuerdo no está publicado, aunque esté firmado, en términos del artículo 72 de la Constitución consideramos que entonces no es norma.

Existe diversa normatividad al respecto. El artículo 19 de la Ley Orgánica del Congreso menciona que los(as) integrantes de la Mesa Directiva podrán ser removidos(as) con el voto de las dos terceras partes de los individuos presentes de la cámara, entre otras, por incumplir los acuerdos del Pleno. Mientras que el artículo 26 de dicha ley señala que los grupos parlamentarios con base en la similitud de sus agendas o en la comunión de sus principios ideológicos, podrán formular acuerdos que se traduzcan en la conformación de mayorías parlamentarias. Los artículos 33 y 34 mencionan que la Junta de Coordinación Política debe impulsar la conformación de acuerdos relacionados con el contenido de las agendas presentadas por los distintos grupos parlamentarios y con el contenido de las propuestas, iniciativas o minutas que requieran de su votación en el pleno, a fin de agilizar el trabajo legislativo.

Por otra parte, la Ley Orgánica del Congreso, en su artículo 34, menciona que a la Junta de Coordinación Política le corresponde, entre otras, presen-

${ }^{64}$ Cfr. Marco Jurídico del Congreso General de los Estados Unidos Mexicanos, en http://www.cddhcu.gob.mx/acerca/marco/indice.htm. 
tar a la Mesa Directiva y al Pleno los proyectos de "puntos de acuerdo", pronunciamientos y declaraciones de la cámara que entrañen una posición política del órgano colegiado. Mientras que el artículo 82 de dicha ley menciona que la Junta de Coordinación Política de la Cámara de Senadores puede presentar al Pleno, por conducto de la Mesa Directiva, propuestas de "puntos de acuerdo", pronunciamientos y declaraciones de la cámara que signifiquen una posición política de la misma. ${ }^{65}$ De ahí que los acuerdos parlamentarios y los puntos de acuerdo son documentos distintos y con diferentes finalidades.

\section{Los usos, prácticas y costumbres parlamentarias}

Los usos, prácticas y costumbres parlamentarias son reconocidos también como fuentes formales del derecho parlamentario, pero es necesario dejar muy claro que éstos están subordinados a la fuente escrita y tienen relación estrecha con el principio de legalidad, ya que éstos no cumplen la condición mínima exigida por dicho principio. ${ }^{66}$

Habrá que acotar que, entre los tres términos anteriores, hay un acercamiento, ya que como hilo conductor tienen un elemento objetivo de actos repetitivos y continuos, de tal forma que "a la doctrina científica siempre le ha resultado difícil llegar a definir con claridad las diferencias entre los usos en el Parlamento por una parte y la costumbre por otra". ${ }^{67}$ Se puede señalar que la costumbre cuenta con el elemento subjetivo que es la aceptación generalizada de ser observable como en el caso de una norma positiva y tiene la ventaja que está reconocida por el derecho civil. Además, dada "la naturaleza esencialmente política y dinámica" de las cámaras, la costumbre como fuente formal viene a flexibilizar el carácter rígido que caracteriza al derecho escrito. ${ }^{68}$ La costumbre se conforma a partir de varios usos, ${ }^{69} \mathrm{y}$ la misma es prácticamente ignorada por las Constituciones (salvo el caso del artículo 2o. de la Constitución mexicana) y lo mismo pasa con la relativa

65 Cfr. http://info4.juridicas.unam.mx/ijure/tcfed/204.htm?s=, consultada el 2 de marzo de 2009.

66 Cfr. Sanz Pérez, Ángel L. y Villacorta Mancebo, Luis, "La costumbre, el uso y otras fuentes no escritas en el derecho parlamentario", op. cit., pp. 321 y 322.

67 Ibidem, p. 317.

68 Serna de la Garza, José María, "Las fuentes formales del derecho parlamentario", Quórum Legislativo, México, núm. 75-76, abril-junio de 2003, p. 55.

${ }^{69}$ Cfr. Aranda Álvarez, Elvira, "Claves para entender el concepto y las fuentes del derecho parlamentario", op. cit., p. 58. 
a la actividad parlamentaria, en donde en sus reglamentos no se plasma de manera expresa. Sin embargo, la costumbre ha dado origen a que se elaboren normas a partir de ésta. ${ }^{70}$

El uso y la práctica son reconocidos también y son fuente del derecho parlamentario, ${ }^{71}$ además, sus características son singulares. El uso está ligado a cuestiones temporales o de grupo, es decir, que se trata de alguna actividad que caracteriza a ciertos individuos por pertenecer a un partido o por el momento histórico en el que se desarrolla el trabajo de una institución. El uso constituye un comportamiento que de ser reiterado en el funcionamiento de una asamblea se conforma como un verdadero hábito de comportamiento para los parlamentarios, sin que de ello se desprenda sanción alguna. Mientras que la práctica, aunque llega a asociarse con la costumbre, ya que está relacionada con actividades reiteradas, pero que caracterizan, sobre todo, por el grado de desarrollo de habilidades, en este caso, de las responsabilidades de los(as) representantes populares. La práctica tiene un valor cuando existe una cierta constancia en soluciones que da a las situaciones similares. ${ }^{72}$ Incluso, existe la Comisión de Reglamentos y Prácticas Parlamentarias. ${ }^{73}$

Para ejemplificar, y en un intento por clasificar este tipo de actividades en las que poco se ha profundizado,${ }^{74}$ podemos señalar lo siguiente:

Una costumbre parlamentaria que se puede distinguir es la relativa a la interpretación del Himno nacional mexicano, en la que hay una serie de actividades que adquieren el carácter de obligatorio aún sin estar puntualmente referidas en una ley; ${ }^{75}$ por ejemplo, cuando en un acto protocolario (apertura y cierre de los periodos de sesiones, entre otros) se interpreta el Himno nacional, pero éste se canta de forma parcial y no con todas sus estrofas.

En cuanto a los usos podemos referirnos a las tácticas dilatorias o de quebranto de la legitimidad, cuando algún(os) grupo(s) parlamentario(s)

${ }^{70}$ Cfr. Sanz Pérez, Ángel L. y Villacorta Mancebo, Luis, "La costumbre, el uso y otras fuentes no escritas en el derecho parlamentario", op. cit., pp. 307 y 310.

71 Cfr. Aguiar de Luque, Luis y Pérez Tremps, Pablo (dirs.), op. cit., pp. 90 y 91.

72 Cfr. Aranda Álvarez, Elvira, "Claves para entender el concepto y las fuentes del derecho parlamentario", op. cit., p. 58.

73 Para profundizar en este tema, consúltese Roldán Xopa, José, op. cit., pp. 87-90.

74 Cfr. Manzanares, Henri, "El régimen parlamentario en Europa occidental", Revista de Estudios Políticos, Madrid, núm. 171-172, 1970, p. 68, y Torres Muro, Ignacio, "Ocho años de derecho parlamentario español. Un comentario bibliográfico (1977-1985)", Revista de la Facultad de Derecho de la Universidad Complutense, Madrid, núm. 10, 1986, p. 227.

75 Ley sobre el Himno Nacional. 
abandona(n) el recinto en el transcurso de una votación sobre un asunto o el uso de las llamadas pancartas.

Finalmente, puede ser considerada como una práctica parlamentaria, por citar algunos casos, cuando los(as) congresistas o parlamentarios(as) están en los edificios de su Cámara, pero al momento de requerir su voto en el Pleno concurren a éste al llamado de su coordinador(a) parlamentario(a).

\section{Los manuales de organización, de procedimientos o de servicios al público y las condiciones generales de trabajo}

Los manuales de organización, de procedimientos o de servicios al público imponen obligaciones a los(as) servidores(as) públicos(as) de las cámaras del Congreso y ante su incumplimiento pueden fincárseles responsabilidad y sancionárseles; éstos deben publicarse en el órgano oficial de difusión correspondiente.

En este sentido, la SCJN ha sostenido que estos manuales, aunque no tienen la calidad de leyes o reglamentos, constituyen normas obligatorias y sirven de base para determinar causas de responsabilidad administrativa, siempre y cuando la acción u omisión prevista en un caso concreto esté claramente precisada como conducta de determinado(a) servidor(a) público(a), éstos deben publicarse en el Diario Oficial de la Federación, pues sólo así resultarán de observancia obligatoria.

Por otra parte, las condiciones generales de trabajo o los convenios colectivos de trabajo son definidos como aquellos instrumentos de acción sindical y de expresión del derecho de negociación, ${ }^{76}$ reconocidos por la Constitución en su artículo 123. A su vez, son una fuente específica del derecho parlamentario que tiene relación con los(as) trabajadores(as) del Congreso, ya que ahí se regulan sus condiciones de trabajo. Los mismos también deben de hacerse públicos, y sí éstos se vulneran, también se vulneran los derechos fundamentales en materia laboral.

\section{Los estatutos de los partidos y de las fracciones}

o grupos parlamentarios

Los partidos políticos aparecen regulados por el Cofipe y por sus propios estatutos, y las fracciones parlamentarias son reguladas por estos últimos,

76 Cfr. Aguiar de Luque, Luis y Pérez Tremps, Pablo (dirs.), op. cit., p. 91. 
consideradas como órganos en el seno de los parlamentos, congresos o asambleas. "Como cuerpo normativo, los estatutos de los partidos políticos y de las fracciones o grupos políticos en el derecho parlamentario juegan un papel indirecto". ${ }^{77}$ Tanto la normatividad sobre derecho electoral como del derecho parlamentario plasman la existencia de dichos estatutos y, al ser normas, éstos deben de ser publicados y alcance de todos, principalmente de los miembros de partidos políticos y de los parlamentarios para garantizar el respeto de sus derechos humanos plasmados en esos documentos. Asimismo, es un requisito la elaboración y presentación de los mismos en las instancias competentes; por ejemplo, los estatutos de los grupos parlamentarios deben ser entregados para que éstos se puedan constituir al interior de la respectiva cámara (artículos 26 y 72 de la Ley Orgánica del Congreso).

\section{La jurisprudencia}

Aunque se podría pensar que para el Congreso no se establece regulación acerca de la jurisprudencia "congresional", ${ }^{78}$ es importante porque se trata de una función constitucional a cargo del Poder Judicial. La jurisprudencia está contemplada en el artículo 94 constitucional que prevé su carácter vinculante; es considerada como otra fuente del derecho parlamentario. Conforme a la Ley de Amparo $^{79}$ constituye jurisprudencia de la SCJN, cinco resoluciones ininterrumpidas en un mismo sentido, con cuando menos ocho votos si es el Pleno o cuatro si es la Sala. También constituye jurisprudencia la resolución del Pleno de la SCJN que dilucida la contradicción de tesis entre las salas de la Corte o entre los Tribunales Colegiados.

Así, la jurisprudencia propiamente parlamentaria, como precedentes que deciden o resuelven recursos o situaciones no reguladas, o que actualizan el contenido de una norma para adaptarla a problemas concretos, tiene un papel importante en el derecho parlamentario. ${ }^{80}$ La misma es

77 Muñoz Q., Hugo Alfonso, "La jurisdicción constitucional y el derecho parlamentario", op. cit., pp. 56 y 57.

${ }^{7}$ Cfr. Roldán Xopa, José, op. cit., p. 91.

79 Cfr. Artículos 192 y 193 de la Ley de Amparo. Reglamentaria de los Artículos 103 y 107 de la Constitución Política de los Estados Unidos Mexicanos.

${ }^{80}$ Cfr. Muñoz Q., Hugo Alfonso, "La jurisdicción constitucional y el derecho parlamentario", op. cit., p. 58. 
considerada como "reductora de privilegios y protectora de derechos", ${ }^{81}$ puesto que la jurisprudencia que resuelve las acciones de inconstitucionalidad o las controversias constitucionales sirve, además, como un medio de control a la actuación del Poder Legislativo en cuanto a su organización y procedimientos parlamentarios. ${ }^{82}$

Relativo a esta materia encontramos los siguientes ejemplos:

En relación con el fuero constitucional (Semanario Judicial de la Federación, Primera Sala, Quinta Época, t. LXXXVII, p. 1877); facultades extraordinarias al Ejecutivo (Segunda Sala, Quinta Época, t. XLVII, p. 5139); Gran Jurado. Decisiones del (Segunda Sala, Quinta Época, t. XXXVIII, p. 753); Cámara de Diputados. Contaduría Mayor de Hacienda. De las facultades (Tribunal Colegiado de Circuito, Octava Época, t. VII, p. 164.); Diputados Federales. Dietas de los. Son considerados ingresos para los efectos del ISR (TCC, Octava Época, t. II, Segunda parte, p. 229); Iniciativas de leyes del presidente de la República. La Cámara de Diputados tiene facultades para adicionarlas (Pleno de la SCJN, Séptima Época, vol. 205-216, parte 1a., p. 58); Congreso de la Unión, la revisión interpuesta por el oficial mayor de la Cámara de Diputados debe desecharse (Pleno de la SCJN, Séptima Época, parte 1a., p. 16); Funcionarios. Fuero constitucional, éste no se prolonga después de haberse separado del cargo (Tercera Sala, Séptima Época, vol. 133-138, parte 4a., p. 38); Cláusula de gobernabilidad (Pleno, Novena Época, t. XIII, p. 625); Sesiones extraordinarias del Congreso de la Unión, convocatoria a. La Comisión Permanente está constitucionalmente facultada para expedirla (Semanario Judicial de la Federación, Pleno, Octava Época, p. 111); Sesiones extraordinarias del Congreso de la Unión, convocatoria a. La Comisión Permanente está constitucionalmente facultada para expedirla (Informe 1988, Pleno, Octava Época, p. 879); Sesiones extraordinarias del Congreso de la Unión, acuerdo por el que se convoca a, publicado como decreto. Tiene validez (Semanario Judicial de la Federación, Pleno, Octava Época, p. 111); Sesiones extraordinarias del Congreso de la Unión, acuerdo por el que se convoca a, publicado como decreto. Tiene validez (Informe 1988, Pleno, Octava Época, p. 879); Renta. La circunstancia de que el periodo de sesiones extraordinarias del Congreso de la Unión en que se aprobó el Decreto que contiene la Ley del Impuesto relativo se haya extendido hasta

81 Arce Janáriz, Alberto, El Parlamento en los tribunales; prontuario de jurisprudencia parlamentaria, Navarra, Editorial Aranzadi, 2004, p. 83.

82 Cfr. Salinas Torre, Armando, op. cit., p. 14. 
el 1o. de enero de 2002, no trasciende a la constitucionalidad del proceso legislativo respectivo (Semanario Judicial de la Federación, Primera Sala, Novena Época, p. 362); Proceso legislativo. Alcances de la convocatoria de la Comisión Permanente para llamar al Congreso de la Unión a un periodo de sesiones extraordinarias (Semanario Judicial de la Federación, Primera Sala, Novena Época, p. 367), y Servidores públicos. Manuales de organización, de procedimientos o de servicios al público, con base en los cuales se les imponen obligaciones y ante su incumplimiento pueden fincárseles responsabilidad y sancionárseles, deben publicarse en el órgano oficial de difusión correspondiente (Semanario Judicial de la Federación, Segunda Sala, Novena Época, p. 515), entre otras, y lo anterior sólo por citar algunos ejemplos.

\section{La doctrina y otras fuentes}

Finalmente, algunos estudios de filosofía del derecho ${ }^{83}$ incluyen a la doctrina como una fuente del mismo. Aunque también se debe acotar que la doctrina sólo tiene carácter de fuente formal del derecho cuando la legislación la señala; por ejemplo, en el contenido de una exposición de motivos de una iniciativa de ley o decreto.

La doctrina comprende todos aquellos estudios o trabajos académicos que se realizan siguiendo un método y que pueden aportar datos susceptibles de ser argumentos racionales a la disciplina jurídica. La doctrina es resultado de la actividad especulativa de los particulares, cuyas conclusiones pueden sentar las bases del criterio de los(as) legisladores(as) e, incluso, de los tribunales. En este sentido, en nuestro país, específicamente existen varias obras sobre el Poder Legislativo como las siguientes:

Por ejemplo, Apuntamientos para el estudio del derecho constitucional mexicano (1871); Derecho constitucional (1875); Curso de derecho constitucional (1888); Elementos de derecho constitucional mexicano (1899); Derecho constitucional mexicano (1931), etcétera, hasta llegar a la actualidad con títulos similares. Asimismo, dicho poder ha sido abordado de manera exclusiva en obras específicas tales; por ejemplo, como Breve estudio sobre el Poder Legislativo (1966); El Poder Legislativo mexicano (1983); El Poder Legislativo en la actualidad (1994); El control del gobierno: función del "Poder Legislativo" (1996); Poder Legis-

${ }^{83}$ Por ejemplo, García Máynez, Eduardo, op. cit., pp. 76 y 77. 
lativo. Gobiernos divididos en la Federación mexicana (1996); Derecho procesal del Poder Legislativo del Estado de México (Apuntes para la caracterización del derecho para interpretar, crear, modificar o suprimir las leyes) (1997); Historia y desarrollo del Poder Legislativo (1997); El Poder Legislativo (1997); El Poder Legislativo del estado libre y soberano de Veracruz-Llave; marco constitucional, legal y reglamentario (1998); La reforma al Poder Legislativo en México (1998); Estructura orgánica y funcional del Poder Legislativo mexicano (2000); Reformas al Poder Legislativo mexicano (2002); La Reforma al Poder Legislativo en México (2003); Poder Legislativo (2004); El Poder Legislativo en México; los diputados de partido: el primer eslabón del cambio (2004); El Poder Legislativo estatal en México; análisis y diagnóstico (2004); Los dueños del Congreso; el Poder Legislativo, secuestrado por dinastías familiares y clanes del dinero (2004); El Poder Legislativo en el Estado mexicano (2005); El Poder Legislativo Federal y local en el marco de un nuevo federalismo (2005), y Gobernabilidad y consenso en el Poder Legislativo: las reformas pendientes (2006). Como rama del derecho han aparecido títulos como el Derecho legislativo mexicano, dirigida por Ochoa Campos, en 1973, posteriormente, en un artículo de Minor Franco (1985), y El procedimiento legislativo mexicano (2005).

Particularmente, respecto del derecho parlamentario existen varias obras, entre éstas y en orden cronológico, tenemos las siguientes: Derecho parlamentario iberoamericano (1987); Derecho parlamentario; la Contaduría Mayor de Hacienda hacia un Tribunal Mayor de Hacienda (1989); Derecho parlamentario (1993); Diccionario de derecho parlamentario mexicano (1993); Derecho parlamentario (1994-1997); Derecho parlamentario (1997); Derecho parlamentario (1999); Teoría del derecho parlamentario (1999); Estudios constitucionales y parlamentarios (1999-2001); Manual del derecho parlamentario o resumen de las reglas (2002); Derecho politico parlamentario; principios, valores y fines (2005); Derecho parlamentario y técnica legislativa en México; principios generales (2006); Tópicos de derecho parlamentario (2007), e Introducción al derecho parlamentario estatal. Estudios sobre los Congresos de los Estados y la Asamblea Legislativa del Distrito Federal (2009). Asimismo, encontramos obras publicadas referentes al término Congreso, y en orden cronológico tenemos las siguientes: Discursos parlamentarios, 1822-1847; el primer Congreso mexicano, el Imperio, la República, la Federación, la Constitución de 1824, Texas, primeras ráfagas centralistas, el Congreso hispanoamericano, la Guerra 
de 1847 (1943); América en el Congreso mexicano (1946); El refrendo y las relaciones entre el Congreso de la Unión y el Poder Ejecutivo (1986); El Congreso de la Unión; integración y regulación (1997); El Congreso mexicano en transición: cambios y continuidades (1999); El Congreso General Mmexicano. Análisis sobre su evolución y funcionamiento actual (2003); El Congreso mexicano después de la alternancia (2003); El Congreso mexicano; historia, organización, funcionamiento y propuestas de reforma (2005); Los servicios de apoyo técnico y su aportación al fortalecimiento del Congreso mexicano (1988-2003) (2005); El Congreso a debate (2006); Marco normativo del Congreso mexicano (2006); Reformas urgentes al marco jurídico del Congreso mexicano (2006); Cambio político y legitimidad funcional; el Congreso mexicano en su encrucijada (2006), y Desencuentro y parálisis en el Congreso mexicano (2006).

Por último, las llamadas convenciones parlamentarias, los precedentes, la corrección parlamentaria, la cortesía y el protocolo parlamentario son figuras elementales que surgen dada la convivencia cotidiana entre los(as) parlamentarios(as), a pesar de que carecen de valor normativo pero que se siguen voluntariamente. ${ }^{84}$

\section{PROPUESTAS Y CONCLUSIONES}

Primera. El derecho parlamentario tiene su origen en Estados Unidos en una obra compilada por Tomas Jefferson, en 1827, titulada Manual del derecho parlamentario, o resumen de las reglas que se observan en el Parlamento de Inglaterra y en el Congreso de los Estados Unidos para la proposición, discusión y decisión de los negocios. Así, el derecho parlamentario es el conjunto de normas que regulan la organización y funcionamiento de las cámaras como órganos que asumen la representación popular en un Estado constitucional y democrático de derecho, y no es suficiente que se le denomine Parlamento, sino que lo esencial es que dicha institución encarne libre y democráticamente la voluntad popular, es decir, que cuando nos referimos al derecho parlamentario puede tratarse también de un Congreso, de una Asamblea, etcétera, y no sólo de un Parlamento.

Segunda. La Constitución define el modo de creación de las normas y el conjunto de relaciones existentes entre éstas. Sin embargo, no hay título, capítulo, o cualquier otra forma de división de un texto constitucional que

84 Cfr. Sanz Pérez, Ángel L. y Villacorta Mancebo, Luis, op. cit., pp. 324-329. 
se refiera expresamente a la configuración de fuentes, por lo que en la actualidad existe una tendencia, como sí ocurre en otros países, para establecer constitucionalmente el sistema de fuentes en el ámbito parlamentario. Con ello se tendría una mayor claridad, seguridad jurídica y sistematización en la materia.

Tercera. Las fuentes formales del derecho parlamentario serán la Constitución; los tratados internacionales; las leyes; los reglamentos; los estatutos; los acuerdos parlamentarios y los puntos de acuerdo; la costumbre, la práctica o el hábito parlamentario; manuales de organización, de procedimientos o de servicios al público y las condiciones generales de trabajo, la jurisprudencia relativa a la institución representativa mexicana, así como la doctrina.

Cuarta. La Constitución mexicana configura la creación y atribución de competencias del H. Congreso de la Unión o Congreso General. En ella se prevé la existencia de éste, su estructura, integración, organización, privilegios, estatutos, así como sus facultades y sus relaciones con el Poder Ejecutivo, con el Poder Judicial, con los Organismos Constitucionales Autónomos, entre otros, y los artículos 1o.-4o., 19-21, 24, 26-29, 32, 37, 41, 44-46, 49-79, 84-90, 93, 95-100, 102, 105, 108-114, 117-119, 121-123, 125, 127, 130-133 y 135 hacen referencia al Congreso o a la Comisión Permanente o alguna de las cámaras del mismo.

Quinta. Es necesario que el Parlamento Latinoamericano creado en 1987 se encuentre integrado por la participación de la ciudadanía, es decir, mediante el sufragio activo y pasivo, con ello tendrá legitimidad, situación que en la realidad no acontece, porque no está regulado de esta forma en el Tratado de Institucionalización del Parlamento Latinoamericano ni en la demás normatividad.

Sexta. En cuanto a los tratados internacionales firmados y ratificados por México, existen tesis de la SCJN, por ejemplo, del 28 de octubre de 2000 y del 20 de marzo de 2007, mediante las que se interpretó que los tratados internacionales, firmados y ratificados se ubican jerárquicamente por encima de las leyes generales, leyes federales y locales y, por lo mismo, en un segundo plano respecto de la Constitución. Esto significa que tanto los poderes legislativos como los poderes judiciales, tanto federales como locales. Lo anterior no es aun jurisprudencia, sino son tesis. A ese respecto, el $10 \mathrm{de}$ junio de 2011 se reforma el artículo 1o. de la Constitución para establecer que todas las personas gozarán de los derechos humanos reconocidos en la Constitución y "en los tratados internacionales de los que el Estado Mexicano 
sea parte", así como de las garantías para su protección, cuyo ejercicio no podrá restringirse ni suspenderse, salvo en los casos y bajo las condiciones que esta Constitución establece. Asimismo, se determina que las normas relativas a los derechos humanos se interpretarán de conformidad con la Constitución y con los tratados internacionales de la materia favoreciendo en todo tiempo a las personas la protección más amplia. Y, finalmente, que todas las autoridades, en el ámbito de sus competencias, tienen la obligación de promover, respetar, proteger y garantizar los derechos humanos de conformidad con los principios de universalidad, interdependencia, indivisibilidad y progresividad. Situación que aplica también respecto del Poder Legislativo en todas sus funciones, organización, estructura, privilegios, estatutos, así como sus facultades con relación a los poderes Ejecutivo y Judicial, por ejemplo.

Séptima. Es necesario que se realicen modificaciones o reformas a los artículos 73, 74, 76, 89 y 133 de la Constitución respecto de los tratados internacionales signados por el presidente de la República y ratificados por el Senado, ya que en otros países se establece claramente que éstos se incorporan al ordenamiento jurídico desde su publicación, tienen sus propios procedimientos legislativos y, además, intervienen ambas cámaras del Congreso o del Parlamento. La trascendencia de este tema radica en que con la firma de tratados internacionales han surgido o se ha dado origen en nuestro país a importantes leyes federales que siguen el procedimiento legislativo contemplado en los artículos 71, 72 y 78 de la Constitución, incluso, dan origen a la modificación de la Constitución y también respecto de la interpretación de la SCJN.

Octava. La Ley Orgánica del Congreso General de 1999, derivada del artículo 70 constitucional, desde su año de publicación se siguió reformando en diversos años, sin embargo, primero, hace falta incorporar en dicha ley nuevas figuras, respetando los derechos humanos de los(as) legisladores(as) que pertenecen o no a un grupo parlamentario, esto es, que no se privilegie a los grupos sobre los(as) legisladores(as) de ambas cámaras; que los(as) parlamentarios(as) cuenten con facultades propias y con relación a la sociedad; que los procedimientos estén debidamente regulados; respetar los derechos de las minorías; la igualdad de los(as) parlamentarios(as), entre otros. Incluso, existe una propuesta para que dicha ley sea denominada como Ley Orgánica y de Funcionamiento del Congreso o se expedida una nueva ley. Segundo, se observa que las leyes orgánicas están reservadas 
para determinada materia y, en algunos países, se requiere de una mayoría calificada para aprobarlas y, en otros casos, hasta referéndum; sin embargo, tampoco éste es el caso de México, ya que sólo se solicita que se cumpla con el quórum de reunión y luego es necesario obtener el voto de la mayoría de los(as) presentes, por lo que es prácticamente sencillo modificar dicha ley en una situación en la que el Congreso esté integrado por mayorías, dejando de lado a las minorías.

Novena. A pesar de diversos intentos aislados por parte de algunos(as) congresistas o parlamentarios(as), no se ejerció durante muchos años la facultad de legislar que tiene cada una de las cámaras del Congreso en materia de reglamentos, en el sentido que cada una de las cámaras está facultada para tener su propio reglamento conforme a lo que señala expresamente el artículo 77 de la Constitución. Situación que cambia hasta 2010, ya que el 4 de junio de ese año se publicó en el Diario Oficial de la Federación el Reglamento del Senado de la República, y lo mismo ocurrió respecto a la Cámara de Diputados el 24 de diciembre de 2010, cuyo reglamento entró en vigor el 1o. de enero de 2011.

Décima. El Reglamento del Canal de Televisión del Congreso General de los Estados Unidos Mexicanos carece de claridad constitucional, ya que el artículo 77 de la Constitución menciona que cada una de las Cámaras del Congreso puede emitir su "Reglamento", es decir, para su régimen interior; sin embargo, el Reglamento de dicho Canal es un reglamento específico. Asimismo, el Canal del Congreso no tiene su fundamento en el artículo 30. de la Ley Orgánica del Congreso que señala, entre otras, que el Congreso tendrá la organización y funcionamiento que establecen los "reglamentos" que cada una de las "cámaras" expida sin la intervención de la otra. Para tener mayor claridad en la materia, sería conveniente una reforma a este artículo 77 constitucional, para que las cámaras puedan emitir "Reglamentos" de diversa índole, como es el Canal del Congreso. O, en todo caso, que este Reglamento específico se incluya la totalidad de su contenido en la Ley Orgánica del Congreso y abrogar el primer Reglamento. El Canal del Congreso pretende ser una televisión pública, pero actualmente para verlo se requiere tener contratado un sistema de televisión por cable.

Décima primera. Ni el Estatuto de la Organización Técnica y Administrativa y del Servicio de Carrera de la Cámara de Diputados ni el Estatuto del Servicio Civil de Carrera del Senado ni tampoco el recientemente publicado Estatuto para los Servicios Parlamentarios, Administrativos y Técnicos del 
Senado de la República se encuentran regulados por un Reglamento específico, sino que se trata de Estatutos que surgen sin claridad de la facultad que tiene cada una de las cámaras del Congreso para emitir su "Reglamento" (artículo 77 de la Constitución). Asimismo, tampoco tienen su fundamento en el artículo 3o. de la Ley Orgánica del Congreso, sin embargo, ésta hace referencia a dichos Estatutos, para la Cámara de Diputados en sus artículos $20,34,38,49,55,56$ y 57, y para el Senado en el artículo 114 . Por lo anterior, es necesario modificar la disposición constitucional para tener mayor claridad, seguridad jurídica y sistematización en la materia. Sin embargo, lo más preocupante es que no funcione el Servicio Civil de Carrera en la Cámara de Diputados y que por un Acuerdo Parlamentario (de menor jerarquía que el Estatuto) éste no funcione, mientras que en la Cámara de Senadores funciona bien.

Décima segunda. Las cámaras; por ejemplo, las comisiones pueden tener reglamentos que organicen su funcionamiento interno, $u$ otros reglamentos en general, sin embargo, éstos al igual que la demás normatividad surgirán, sin claridad, de la facultad que tiene cada una de las cámaras del Congreso para emitir su "reglamento" (artículo 77 de la Constitución).

Décima tercera. El artículo 77, fracción I, de la Constitución establece que cada una de las cámaras puede, sin intervención de la otra, dictar resoluciones económicas relativas a su régimen interior. De igual manera, el artículo 3o. de la Ley Orgánica del Congreso señala que éste y las Cámaras que lo componen tendrán la organización y funcionamiento que establecen la Constitución, la ley, las reglas de funcionamiento del Congreso y de la Comisión Permanente, así como los reglamentos y "acuerdos" que cada una de éstas expida sin la intervención de la otra. Por ello, los acuerdos y puntos de acuerdos parlamentarios están plasmados en la norma constitucional, pero se considera que no existe una regulación precisa de los mismos, se produce su empleo indiscriminado, es decir, en su producción se pierde el rigor conceptual y jurídico, por lo que es necesaria su precisión legislativa, incluido el tema del contenido que pueden tener éstos.

Décima cuarta. Los usos, prácticas y costumbres parlamentarias son reconocidos también como fuentes formales del derecho parlamentario, pero éstos están subordinados a la fuente escrita. Asimismo, son los manuales de organización, de procedimientos o de servicios al público los que imponen obligaciones a los(as) servidores(as) públicos(as) de las cámaras del Congreso y que constituyen normas obligatorias que sirven de 
base para determinar causas de responsabilidad administrativa y, para ser de observancia obligatoria, deben publicarse en el órgano de difusión oficial. De igual forma, son también fuentes de este derecho las condiciones generales de trabajo o los convenios colectivos de trabajo, los estatutos de los partidos políticos o de las fracciones parlamentarias, la jurisprudencia y la doctrina y otras fuentes cuando la legislación las señala.

\section{BIBLIOHEMEROGRAFÍA}

Aguiar de LuQue, Luis y Pérez Tremps, Pablo (dirs.), Veinte años de jurisdicción constitucional en España, Valencia, Tirant lo Blanch, 2002.

ARANDA ÁlvAREZ, Elvira, "Claves para entender el concepto y las fuentes del derecho parlamentario", Revista de las Cortes Generales, Madrid, núm. 66, tercer cuatrimestre de 2005.

ARCE JANÁRIZ, Alberto, El Parlamento en los tribunales; prontuario de jurisprudencia parlamentaria, Navarra, Editorial Aranzadi, 2004.

ARTEAGA NAVA, Elisur, "Las Constituciones estatales y sus reformas", Alegatos, México, núm. 6, 1987.

BARRAGÁN, José, “Algunas consideraciones de carácter histórico sobre el régimen interno del Congreso de la Unión”, Revista Mexicana de Estudios Parlamentarios, México, núm. 2, 1991.

Berlín Valenzuela, Francisco, Derecho parlamentario, México, Fondo de Cultura Económica, 1993.

CARBonell, Miguel, Constitución, reforma constitucional y fuentes del derecho en México, México, Porrúa-UNAM, 2008.

, "El significado de las fuentes del derecho, una perspectiva constitucional”, Quórum Legislativo, México, núm. 75-76, abril-junio de 2003.

- (comp.), Instrumentos jurídicos internacionales en materia de no discriminación, México, Consejo Nacional para Prevenir la Discriminación, 2006.

CÁrdenas Gracia, Jaime F., Una Constitución para la democracia. Propuestas para un nuevo orden constitucional, México, UNAM, 1996.

Constitución Política de los Estados Unidos Mexicanos, 5a. ed., México, Comisión Nacional de los Derechos Humanos, 2002.

Constitución Política de los Estados Unidos Mexicanos, 165a. ed., México, Porrúa, 2012.

Cossío, José Ramón y RAIGOSA, Luis, "Régimen político e interpretación 
constitucional", Revista El País, México, marzo de 1996.

Chávez, Víctor, "Posibles cambios a la Ley Orgánica del Congreso", El Financiero, México, 18 de diciembre de 1996.

Diario Oficial de la Federación, México, 20 de julio de 1994; 24 de agosto de 2009; 4 de junio de 2010; 24 de diciembre de 2010; 10 de junio de 2011, que contiene el Decreto por el que se modifica la denominación del Capítulo I del Título Primero y reforma diversos artículos de la Constitución Política de los Estados Unidos Mexicanos.

FiX-FierRo, Héctor, CARPIZO, Jorge, VALADÉS, Diego et al., en BARCELÓ RoJAS, Daniel (coord.), La Reforma del Estado. Propuesta del IIJUNAM para la actualización de las relaciones entre poderes del sistema presidencial mexicano, México, UNAM, Instituto de Investigaciones Jurídicas-Senado de la República, 2009.

FiX-Zamudio, Héctor y Valencia CARmona, Salvador, Derecho constitucional mexicano y comparado, 7a. ed., México, Porrúa-UNAM, 2010. Gaceta Parlamentaria, Cámara de Diputados, núm. 2987-III, martes 13 de abril de 2010.

GARABITO MARTíNEZ, Jorge, "Las fuentes axiológicas del derecho parlamentario", Quórum Legislativo, México, núm. 75-76, abril-junio de 2003. __ _ "Reseña de la Ley Orgánica del Congreso General de los Estados Unidos Mexicanos", Quórum Legislativo, México, núm. 81, abril-junio de 2005.

GARCÍA MÁYNEZ, Eduardo, Introducción al estudio del derecho, 42a. ed., México, Porrúa, 1991.

GARCÍA RAMíREZ, Sergio (coord.), La jurisprudencia de la Corte Interamericana de Derechos Humanos, México, UNAM-CIDH, 2001.

GIL ZUARTH, Roberto et al., "Ponencias Foro Reglamento de Debates de las Cámaras del H. Congreso de la Unión”, Quórum Legislativo, México, núm. 83, octubre-diciembre de 2005.

http://gaceta.diputados.gob.mx/Gaceta/59/2005/dic/20051220.html, consultada el 13 de abril de 2010.

http://info4.juridicas.unam.mx/ijure/fed/9/106.htm?s=, consultada el 2 de marzo de 2009.

http://www.juridicas.unam.mx/infjur/leg/constmex/, consultada el 26 de febrero de 2009, el 17 de agosto de 2009 y el 19 de enero de 2010. http://www.juridicas.unam.mx/infjur/leg/constmex/pdf/27042010R.pdf, consultada el 30 de septiembre de 2010. 
http://www.juridicas.unam.mx/infjur/leg/constmex/pdf/29072010R.pdf, consultada el 30 de septiembre de 2010.

http://info4.juridicas.unam.mx/ijure/tcfed/204.htm?s=, consultada el 2 de marzo de 2009.

http://www.cddhcu.gob.mx/acerca/marco/indice.htm.

http://www.diputados.gob.mx/LeyesBiblio/marjur/marco/senado/Senado estatuto_27dic11.pdf, consultada el 12 de abril de 2012.

http://www.diputados.gob.mx/LeyesBiblio/ref/locg.htm, consultada el 3 de marzo de 2009, el 19 de enero y el 30 de septiembre de 2010, y el 12 de abril de 2012.

http://www.diputados.gob.mx/LeyesBiblio/ref/rgic.htm, consultada el 3 de marzo de 2009, 19 de enero y 15 de abril de 2010.

http://www.juridicas.unam.mx/infjur/leg/constmex/, consultada el 26 de febrero de 2008, el 30 de septiembre de 2010 y el 12 de abril de 2012. http://www.senado.gob.mx/admon/estatuto.html y http://www.senado.gob.

$m x /$ iilsen/, consultadas el 30 de septiembre de 2010.

http://www.senado.gob.mx/index.php? ver $=s e n \& m n=1 \& s m=6$, consultada el 30 de septiembre de 2010.

HuERTAS, Fernando, "Los canales de televisión parlamentarios", en PAU I VALL, Francesc (coord.), Parlamento y Comunicación (Nuevos Retos); XI Jornadas de la Asociación Española de Letrados de Parlamentos, Madrid, Editorial Tecnos, 2005.

Ley Orgánica del Congreso General de los Estados Unidos Mexicanos, México, Talleres Gráficos de la Cámara de Diputados, 1990.

Madrazo, Jorge, "Comentario al artículo 135", Constitución Política de los Estados Unidos Mexicanos. Comentada y concordada, 15a. ed., México, Porrúa-UNAM, 2000, t. V.

MANZANARES, HENRI, "El régimen parlamentario en Europa Occidental", Revista de Estudios Políticos, Madrid, núm. 171-172, 1970.

Mora-DonatTo, Cecilia, "Urgente rediseñar el servicio de carrera del Congreso mexicano", Cuestiones Constitucionales. Revista Mexicana de Derecho Constitucional, México, núm. 19, julio-diciembre de 2008. Moreno URIEGAS, María de los Ángeles, "El Poder Legislativo y el proyecto nacional”, Quórum, México, núm. 26, 1994.

MuÑOZ Q., Hugo Alfonso, "La jurisdicción constitucional y el derecho parlamentario", en BERTOLINI, Anarella y FERNÁNDEZ, Hubert (eds.), La jurisdicción constitucional y su influencia en el Estado de derecho, San José, Costa Rica, Editorial Universidad Estatal a Distancia, 1999. 
Olamendi Torres, Patricia, Mujeres, familia y ciudadanía, México, UNIFEM, 2008.

Отто, Ignacio de, Derecho constitucional, Barcelona, Ariel, 1988.

QUIROGA LAVIÉ, Humberto, "El derecho parlamentario en la ciencia jurídica”, Derecho parlamentario iberoamericano, México, Porrúa, 1997.

Pedroza de la Llave, Susana Thalía, "Concentración de medios y pluralismo: el marco jurídico del canal de televisión del Congreso mexicano", en CARPIZO, Jorge y CARBONELl, Miguel (coords.), Derecho a la información y derechos humanos; estudios en homenaje al maestro Mario de la Cueva, México, UNAM, 2000.

__ "La nueva Ley Orgánica del Congreso General de los Estados Unidos Mexicanos de 1999 y su funcionamiento interno", Boletín Mexicano de Derecho Comparado, México, Nueva Serie, año XXXIII, núm. 99, septiembre-diciembre de 2000.

, "Las fuentes del derecho parlamentario en México", Documento de trabajo, núm. 138, México, diciembre de 2009.

_ - "Notas actuales sobre el derecho parlamentario en los sistemas de gobierno de asamblea, parlamentario, presidencial y el semipresidencial o semiparlamentario," Revista de la Facultad de Derecho de México, México, t. LXI, núm. 255, enero-junio de 2011.

y García HuAnte, Omar (comps.), Compilación de instrumentos internacionales de derechos humanos. Firmados y ratificados por México 1921-2003, México, CNDH, ts. I y II, 2004.

PÉREZ NORIEGA, Fernando, "Fuentes del derecho parlamentario", Quórum Legislativo, México, núm. 75-76, abril-junio de 2003.

RAMíREZ MARÍN, Juan, "Del Reglamento para el Gobierno Interior del Congreso General de los Estados Unidos Mexicanos", Quórum Legislativo, México, núm. 90, julio-septiembre de 2007.

RECASÉNS SiCHES, Luis, Introducción al estudio del derecho, 2a. ed., México, Porrúa, 1990.

Reglamento interior de las comisiones de la Asamblea Legislativa del Distrito Federal (publicado en la Gaceta Oficial del Distrito Federal el 30 de diciembre de 2003), disponible en http://www.asambleadf.gob.mx/ al/pdf/010804000062.pdf.

RoldÁn XopA, José, El sistema de fuentes del Senado, México, Senado de la República-ITAM-Miguel Ángel Porrúa, 2003.

SANZ PÉREZ, Ángel L. y VillacorTA MANCEBo, Luis, "La costumbre, el uso y otras fuentes no escritas en el derecho parlamentario", Corts. 
Anuario de Derecho Parlamentario, España, núm. 17, 2006.

SAlgado Loyo, Alfredo (coord.), Ley Orgánica del Congreso General de los Estados Unidos Mexicanos; Comentada, México, Cámara de Diputados, LX Legislatura, 2006.

SALINAS TORRE, Armando, "Reflexiones sobre las fuentes del derecho parlamentario mexicano", Quórum Legislativo, México, núm. 75-76, abriljunio de 2003.

SAnTAOlalla, Fernando, Derecho parlamentario español, Madrid, Espasa Calpe, 1990.

SAnz PÉRez, Ángel L. y Villacorta Mancebo, Luis, "La costumbre, el uso y otras fuentes no escritas en el derecho parlamentario", Corts. Anuario de Derecho Parlamentario, Valencia, núm. 17, 2006.

SCHMILl ORDÓÑEZ, Ulises, El sistema de la Constitución mexicana, México, Porrúa, 1977.

SERna DE LA GARZA, José María, "Las fuentes formales del derecho parlamentario", Quórum Legislativo, México, núm. 75-76, abril-junio de 2003.

TALAVERA, Abraham, "México: reforma política y reforma electoral”, Quórum, México, núm. 10, 1993.

TORRES Muro, Ignacio, "Ocho años de derecho parlamentario español. Un comentario bibliográfico (1977-1985)", Revista de la Facultad de Derecho de la Universidad Complutense, Madrid, núm. 10, 1986.

Tosi, Silvano, Diritto parlamentare, Milán, Giuffrè, 1993.

TROBO, Jaime Mario, "Diplomacia parlamentaria, una nueva dimensión de la política exterior", Revista Parlamentaria Iberoamericana, Madrid, núm. 7, 1998.

VALADÉS, Diego, La parlamentarización de los sistemas presidenciales, 2a. ed., México, UNAM-El Colegio Nacional, 2008.

VillabOnA, María Pilar, "La Constitución mexicana de 1917 y la española de 1931", Revista de Estudios Políticos, Madrid, núm. 31-32, 1983. Villoro TORAnZO, Miguel, Introducción al estudio del derecho, 2a. ed., México, Porrúa, 1990.

Fecha de recepción: 27 de enero de 2010.

Fecha de dictamen: 10 de febrero de 2010. 